Cronfa - Swansea University Open Access Repository

This is an author produced version of a paper published in :

Cognitive Neuropsychology

Cronfa URL for this paper:

http://cronfa.swan.ac.uk/Record/cronfa30945

\title{
Paper:
}

Towler, J. \& Eimer, M. (2012). Electrophysiological studies of face processing in developmental prosopagnosia: Neuropsychological and neurodevelopmental perspectives. Cognitive Neuropsychology, 29(5-6), 503-529. http://dx.doi.org/10.1080/02643294.2012.716757

This article is brought to you by Swansea University. Any person downloading material is agreeing to abide by the terms of the repository licence. Authors are personally responsible for adhering to publisher restrictions or conditions. When uploading content they are required to comply with their publisher agreement and the SHERPA RoMEO database to judge whether or not it is copyright safe to add this version of the paper to this repository. http://www.swansea.ac.uk/iss/researchsupport/cronfa-support/ 
This article was downloaded by: [Birkbeck College]

On: 16 October 2012, At: 03:20

Publisher: Psychology Press

Informa Ltd Registered in England and Wales Registered Number: 1072954 Registered office:

Mortimer House, 37-41 Mortimer Street, London W1T 3J H, UK

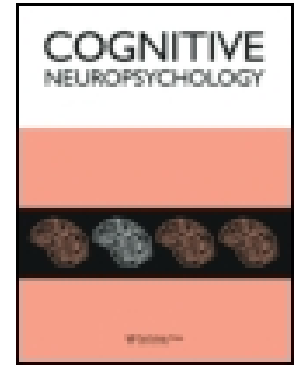

\title{
Cognitive Neuropsychology
}

Publication details, including instructions for authors and subscription information:

http:// www.tandfonline.com/loi/pcgn20

\section{Electrophysiological studies of face processing in developmental prosopagnosia: Neuropsychological and neurodevelopmental perspectives}

\author{
J ohn Towler ${ }^{a}$ \& Martin Eimer ${ }^{\text {a }}$ \\ a Department of Psychological Sciences, Birkbeck College, University of \\ London, UK
}

Version of record first published: 16 Oct 2012.

To cite this article: J ohn Towler \& Martin Eimer (2012): Electrophysiological studies of face processing in developmental prosopagnosia: Neuropsychological and neurodevelopmental perspectives, Cognitive Neuropsychology, DOI: 10.1080/ 02643294.2012.716757

To link to this article: http:// dx. doi.org/10.1080/02643294.2012.716757

\section{OFirst}

\section{PLEASE SCROLL DOWN FOR ARTICLE}

Full terms and conditions of use: http://www.tandfonline.com/page/terms-and-conditions

This article may be used for research, teaching, and private study purposes. Any substantial or systematic reproduction, redistribution, reselling, loan, sub-licensing, systematic supply, or distribution in any form to anyone is expressly forbidden.

The publisher does not give any warranty express or implied or make any representation that the contents will be complete or accurate or up to date. The accuracy of any instructions, formulae, and drug doses should be independently verified with primary sources. The publisher shall not be liable for any loss, actions, claims, proceedings, demand, or costs or damages whatsoever or howsoever caused arising directly or indirectly in connection with or arising out of the use of this material. 


\title{
Electrophysiological studies of face processing in developmental prosopagnosia: Neuropsychological and neurodevelopmental perspectives
}

\begin{abstract}
John Towler and Martin Eimer
Department of Psychological Sciences, Birkbeck College, University of London, UK

People with developmental prosopagnosia (DP) show severe face-recognition deficits that typically emerge during childhood without history of neurological damage. We review findings from recent event-related brain potential (ERP) studies of face perception and face recognition in DP. The generic face-sensitivity of the N170 component is present in most DPs, suggesting rapid categoryselective streaming of facial information. In contrast, DPs show atypical N170 face inversion effects, indicative of impaired structural encoding, specifically for upright faces. In line with neurodevelopmental accounts of DP, these effects are similar to those observed for other developmental disorders, as well as for younger children and older adults. Identity-sensitive ERP components (N250, P600f) triggered during successful face recognition are similar for DPs and control participants, indicating that the same mechanisms are active in both groups. The presence of covert face-recognition effects for the N250 component suggests that visual face memory and semantic memory can become disconnected in some individuals with DP. The implications of these results for neuropsychological and neurodevelopmental perspectives on DP are discussed.
\end{abstract}

Keywords: Face processing; Face recognition; Face perception; Prosopagnosia; Event-related brain potentials; Visual cognition.

Prosopagnosia is a severe deficit of visual face recognition in the absence of low-level visual impairments and intellectual disability. Individuals who have this condition may also experience difficulties in processing other aspects of faces, such as expressions of emotion, or may even show more general deficits in object recognition. Traditionally, prosopagnosia was regarded as a relatively rare consequence of acquired head injury or stroke (Bodamer, 1947). However, another type of prosopagnosia of a developmental origin without any apparent brain damage has recently been found to be much more common than prosopagnosia acquired in adulthood (AP). Current estimates of

Correspondence should be addressed to Martin Eimer, Department of Psychological Sciences, Birkbeck College, University of London, Malet Street, London WC1E 7HX, UK. (E-mail: m.eimer@bbk.ac.uk).

This research was supported by a grant from the Economic and Social Sciences Research Council (ESRC), UK. Our thanks to Angela Gosling, Joanna Parketny, Friederike Zimmermann, and Brad Duchaine for their contributions to the work reviewed in this paper, to Margot Taylor for providing us with the data for Figure 3, and to Annette Karmiloff-Smith for comments on an earlier version of the manuscript.

(C) 2012 Psychology Press, an imprint of the Taylor \& Francis Group, an Informa business 
the prevalence of developmental prosopagnosia (DP) range from $1.9 \%$ to $2.5 \%$ in different ethnic populations (Kennerknecht et al., 2006; Kennerknecht, Pluempe, \& Welling, 2008), and both family and twin studies suggest a strong genetic contribution for such face-recognition impairments (Duchaine, Germine, \& Nakayama, 2007a; Lee, Duchaine, Nakayama, \& Wilson, 2010; Wilmer et al., 2010; Zhu et al., 2010).

Because DP has only recently become the focus of systematic research, relatively little is known about its developmental origin and trajectory, the nature of the perceptual and cognitive processes that are affected, and its neural basis. The aim of this paper is to review recent research that has employed brain activity measures such as functional magnetic resonance imaging (fMRI), magnetoencephalography (MEG), and electroencephalography (EEG) to identify neural correlates of developmental prosopagnosia, and to understand the nature of the face-processing deficits in individuals with DP. The main focus of this review will be on recent findings from event-related brain potential (ERP) studies that investigated and compared the temporal dynamics of face perception and face recognition in participants with DP and in control participants. On a more theoretical level, we will discuss whether the neuropsychological model that is appropriate when interpreting the face-processing impairments in patients with acquired prosopagnosia is also sufficient for an understanding of developmental prosopagnosia, or whether additional neurodevelopmental observations and considerations need to be taken into account.

The first section contrasts traditional neuropsychological and neurodevelopmental approaches to the study of cognitive function and dysfunction in general, and face processing in particular, and raises the possibility that a neurodevelopmental perspective might be particularly useful for the study of DP and its neural and functional basis. After a brief summary of insights into the functional architecture of face processing and its disruption in $\mathrm{AP}$ and $\mathrm{DP}$ in the second section, the two main review sections will discuss results from recent ERP studies into impairments of face perception (third section) and face recognition (fourth section) in participants with DP. The final section presents a summary of the main findings and their implications for neuropsychological and neurodevelopmental perspectives on DP.

\section{ACQUIRED AND DEVELOPMENTAL PROSOPAGNOSIA: NEUROPSYCHOLOGICAL VERSUS NEURODEVELOPMENTAL APPROACHES}

Studies of patients with acquired lesions to circumscribed brain areas have traditionally been crucial for identifying and localizing specific cognitive functions in the intact adult brain (Shallice, 1988). In particular, the discovery of double dissociations of normal and impaired functions in patients with distinct brain lesions is a powerful indicator of functionally specialized cognitive modules. This classic neuropsychological approach has also been successfully applied to the study of face processing. Insights from patients with AP have been instrumental in elucidating the processes underlying face perception and recognition in individuals without face-processing impairments (Bruce and Young, 1986; Ellis and Young, 1996; Young, 1992). Importantly, once neuropsychologically inspired cognitive models of face processing have been developed, they can then also be used to interpret and categorize individual patterns of deficits in patients with $\mathrm{AP}$, by linking them to selective impairments of functionally defined stages of face perception or recognition.

The neuropsychological literature reveals that deficits observed for individual patients can be remarkably specific across and even within cognitive domains (e.g., Dehaene, Piazza, Pinel, \& Cohen, 2003; Happé, Brownell, \& Winner, 1999; Mahon \& Caramazza, 2009). For example, there are relatively rare cases of patients with "pure" AP who show specific face-recognition impairments in the absence of more general deficits in the recognition of non-face objects (e.g., Busigny, Joubert, Felician, Ceccaldi, \& Rossion, 2010), and even rarer cases of patients who show the reverse pattern 
of intact face processing with impaired object recognition (Moscovitch, Winocur, \& Behrmann, 1997). The existence of these patients appears to provide strong evidence for the domain-specificity and modularity of a dedicated face-processing system in the adult brain (e.g., Kanwisher, 2000; Kanwisher \& Yovel, 2006; but see also Gauthier, Behrmann, \& Tarr, 1999; Tarr \& Gauthier, 2000). In addition to lending general support to modular accounts, neuropsychological studies of intact and impaired face processing have shaped the development of functional models of human face-processing system. Bruce and Young (1986) used evidence from case studies of AP to motivate a hierarchical system of face processing where different types of information conveyed by faces (identity, emotional expression, direction of gaze, etc.) are extracted independently and in parallel. An initial perceptual "structural encoding" stage constructs view-dependent and expression-independent descriptions. The recognition of an individual face involves matching these "structural codes" with visual descriptions of a familiar face that are stored as face-recognition units (FRUs) in visual memory. Activation of FRUs results in the subsequent retrieval of person-specific semantic and episodic representations, via modalityunspecific person identity nodes (PINs). According to Bruce and Young (1986), the analysis of more variable aspects of faces, such as gaze and emotional expression, takes place in parallel with and independent of the processes that result in face recognition. This hypothesis is supported by double dissociations between the recognition of identity and emotional expression across different patients with AP (Calder, Keane, Manes, Antoun, \& Young, 2000; Calder et al., 1996; Young, Newcombe, de Haan, Small, \& Hay, 1993; for a critical review, see Calder \& Young, 2005).

Further neuropsychological support for the model proposed by Bruce and Young (1986) comes from patients with AP who are able to match unfamiliar faces successfully, but are unable to recognize previously familiar faces, along with patients who show the reverse pattern (Malone, Morris, Kay, \& Levin, 1982; Young et al., 1993; but see Duchaine and Weidenfeld, 2003, for a critical review), suggesting dissociations between disruptions of structural encoding and impaired access to stored FRUs in visual memory. The case of patient ME (de Haan, Young, \& Newcombe, 1991), who can make familiarity decisions about familiar faces but is unable to retrieve specific semantic or episodic information about these individuals, suggests intact FRUs and a deficit in the subsequent access to person-specific semantic information via PINs. Furthermore, the existence of patients with anomia who can recognize faces and give some semantic details, but are unable to name them (Flude, Ellis, \& Kay, 1989; although see Burton \& Bruce, 1992), points towards a separable stage of name retrieval. Many distinctions proposed by Bruce and Young (1986) have stood the test of time, and additional modelling and neuropsychological research have expanded this model (Ellis \& Young, 1990; Young, 1992; Young \& Burton, 1999). More recent advances have come from mappings from cognitive/functional descriptions of the face-processing architecture onto neural systems which implement these functions (Calder \& Young, 2005; Haxby, Hoffman, \& Gobbini, 2000). In summary, the neuropsychological approach has provided considerable support for the modular nature of human face processing, and has inspired most current models of face perception and recognition. In the context of this approach, face perception or face-recognition deficits observed in patients with AP are interpreted in terms of focal impairments of a module (or series of interconnected modules) within an otherwise intact face-processing system.

The cognitive neuropsychological framework is appropriate for the study of acquired prosopagnosia, which results when brain damage disrupts a previously normally functioning face-processing system. However, it is not at all clear whether the rules of the game change when investigating the pattern of abilities and impairments that are observed in developmental disorders. In fact, numerous authors have challenged the view that cognitive neuropsychological methods and the associated concept of intact and damaged modules are always appropriate for the study of development and its disorders (Bishop, 1997;

COGNITIVE NEUROPSYCHOLOGY, 2012, 00 (0) 
Karmiloff-Smith, 1998; Karmiloff-Smith, Scerif, \& Ansari, 2003; Thomas \& Karmiloff-Smith, 2002; Young, 2011). A critical argument in this debate is that neurodevelopmental disorders may violate the core assumption of the double dissociation logic, that observed performance deficits reflect specific dysfunctions of separable processing modules within an otherwise normally organized and functioning system (e.g., Caramazza, 1986; Shallice, 1988). In individuals with neurodevelopmental disorders, the possibility needs to be taken into account that the cognitive system as a whole, or major parts of the cognitive system such as the mechanisms responsible for visual recognition, may have never achieved the architecture that is observed in the typical adult cases. In other words, it is far from obvious that developmental disorders will produce a cognitive system that is normal except for the absence of specific modular component processes. It is also not clear that the absence of such processes will only have local effects within a given domain, and no impact on other cognitive processes or the interactions between them. Even a relatively selective deficit such as DP may not be completely analogous to acquired disorders: a lifetime of learning to compensate for this deficit might result in a cognitive or neural architecture where systems are recruited for functions that they would not normally fulfil in the typical case.

Neurodevelopmental or neuroconstructivist approaches to the study of developmental disorders emphasize the role of interactions between external input and internal cognitive architecture during ontogenesis in transforming the highly interconnected brain in infancy into the relatively modular and specialized brain mechanisms that are often observed in adulthood (Oliver, Johnson, Karmiloff-Smith, \& Pennington, 2000; Westermann et al., 2007; Mareschal et al., 2007). These approaches go beyond the common dichotomy between domain-specific and domain-general processes by emphasizing the role of domainrelevant mechanisms which may become progressively specialized and modularized over the course of development (Karmiloff-Smith, 1998). In this context, the interpretation of developmental disorders and their neural and cognitive effects differs from the standard neuropsychological model: instead of reflecting damage to modular subsystems within an otherwise intact cognitive architecture, they are interpreted as the consequence of atypical trajectories of neural and cognitive development. Such deviations from typical developmental pathways may be traced back to early perturbations of relatively low-level processes (e.g., Brown et al., 2003), and result in neural and cognitive systems that operate in a qualitatively different fashion than the systems observed in typical adults (Karmiloff-Smith, 1992, 2009).

Neurodevelopmental and neuropsychological modular accounts offer different perspectives on the nature of developmental disorders. From a neuropsychological view, such disorders are often viewed as the result of damage to innately specified cognitive modules (e.g., grammar or face processors) which are domain-specific from birth (Kanwisher \& Yovel, 2006; McKone, Crookes, \& Kanwisher, 2009). In contrast, neurodevelopmental accounts point to low-level properties of visual stimuli and response preferences in the developing visual system as the initial source of processing biases towards certain stimulus categories such as faces, which can result in the emergence of category-specific cognitive systems in the course of development (e.g., Johnson, Grossman, $\&$ Cohen Kadosh, 2009). For example, dissociations between individuals with Williams syndrome (WS) and specific language impairment (SLI) have often been used to support claims of an innately prespecified "syntax modules" (e.g., Pinker, 1999) or face-processing systems, because WS individuals have spared language and face processing skills in spite of often severe general cognitive and visuo-spatial impairments, whereas SLI individuals have impaired language abilities alongside otherwise intact perceptual and cognitive skills. However, the hypothesis that language and face processing are spared and operate normally in individuals with WS (Bellugi, Lichtenberger, Jones, Lai, \& St George, 2000) has been challenged by demonstrating atypical developmental trajectories and cognitive mechanisms in these domains (Donnai \& Karmiloff-Smith, 2000; 
Karmiloff-Smith et al., 2003, 2004; Laing et al., 2002). Even though performance in behavioural tests of face processing is often in the normal range, closer scrutiny reveals that individuals with WS show an atypical reliance on featurebased information to support this performance. They are less efficient at detecting configural changes in upright faces, and are less sensitive to face inversion than controls (Deruelle, Mancini, Livet, Cassé-Perrot, \& de Schonen, 1999). Accordingly, typical behavioural face inversion effects emerge only weakly in individuals with WS over development (Karmiloff-Smith et al., 2004), or not at all (Annaz, Karmiloff-Smith, Johnson, \& Thomas, 2009).

These considerations may have important implications for the study of developmental prosopagnosia. Individuals with DP show severe impairments of face recognition that often emerge in early childhood, and are assumed to result from a failure to develop normally functioning face-processing mechanisms (e.g., Duchaine, 2011). Even though some adult DPs show remarkably face-specific deficits (Duchaine, Yovel, Butterworth, \& Nakayama, 2006), the question remains as to whether impaired face processing in DP can be fully accounted for by a modular neuropsychological approach, or whether a neurodevelopmental perspective might provide additional useful insights. Should we always interpret the pattern of face perception and face-recognition impairments in adult individuals with DP as evidence for localized dysfunctions of specific modular subprocesses within an otherwise intact face-processing system? Or are these impairments at least sometimes the result of qualitative differences in face processing between DPs and unimpaired individuals that can be traced back to atypical developmental trajectories?

In the remaining sections of this paper, we will discuss these questions on the basis of a selective review of recent neuroscientific studies of the mechanism of face perception and recognition in DP. After a brief summary of fMRI studies of impaired and intact face processing, we will focus on recent ERP experiments that have investigated the temporal dynamics of face perception and face recognition in individuals with DP, and compared it to the mechanisms of face perception and recognition in people with intact face processing.

\section{NEUROIMAGING STUDIES OF AP AND DP}

The core regions involved in face processing, as identified with $\mathrm{fMRI}$ measures, include the occipital face area (OFA) in the inferior occipital gyrus (see Pitcher, Duchaine, Walsh, Yovel, and Kanwisher, 2011a, for review), the fusiform face area (FFA) in the middle fusiform gyrus (Kanwisher, McDermott, \& Chun, 1997; Kanwisher \& Yovel, 2006), and posterior parts of the superior temporal sulcus (pSTS; Haxby et al., 2000). Structural MRI studies of patients with AP have revealed that the posterior part of this core network is typically damaged, either bilaterally or in the right hemisphere, with lesions often centred in occipito-temporal areas (e.g., Barton, 2008). Findings from fMRI studies of patients with AP are somewhat less clear. For example, there are patients who have lesions to bilateral or right inferior occipital regions including the OFA and therefore no face-sensitive OFA activity, but still show activation of the FFA and pSTS (Rossion et al., 2003; Steeves et al., 2006). This suggests that the architecture of the core face-processing system may not be strictly linear (e.g., Haxby et al., 2000), and that there is direct visual input to higher-level face-processing areas that bypass more posterior cortical regions such as the OFA. Prosopagnosia can also result from damage to anterior regions of temporal cortex that are not implicated in the core face-processing system, although the symptoms associated with damage to these regions appear to be more memory-related and less perceptual than the deficits found as a consequence of occipito-temporal lesions (Barton, 2008; Kanwisher \& Barton, 2011). In line with the neuropsychological model, these neuroimaging studies demonstrate that acquired prosopagnosia is often the result of damage to relatively focal regions of cortex that are involved in distinct aspects of face processing.

COGNITIVE NEUROPSYCHOLOGY, 2012, 00 (0) 
In AP, lesions typically involve one or more of the core regions that implement relatively early visual stages of face perception (Barton, 2008). Such lesions will have obvious knock-on effects on later processing stages that depend on the availability of intact visual face representations (Bruce \& Young, 1986).

Despite similar behavioural deficits, the neuroimaging evidence is less clear-cut in developmental prosopagnosia. Although DPs do not have any obvious brain damage, there is now some evidence for structural and white-matter connectivity differences compared to individuals with typical face processing (e.g., Behrmann, Avidan, Marotta, \& Kimchi, 2007; Garrido et al., 2009; Thomas et al., 2008). Findings from fMRI studies of individuals with DP remain inconclusive. Evidence that the core face-processing architecture may be intact in DP comes from the case of YT (Hasson, Avidan, Deouell, Bentin, \& Malach, 2003), who showed normal face-selective responses in the left and right FFA and the right OFA, despite severe behavioural difficulties in recognizing known individuals. Similarly, four other DPs also showed normal category-sensitive activity in the FFA and in other ventral occipitotemporal areas to faces, relative to buildings and other objects (Avidan, Hasson, Malach, \& Behrmann, 2005). A recent investigation found relatively subtle functional differences in the face selectivity of fusiform gyrus between DPs and controls (Furl, Garrido, Dolan, Driver, \& Duchaine, 2011), but there were no group differences in face-specific repetition suppression effects in these regions. If face-selective regions identified by fMRI can be mapped onto cognitively defined face-processing stages (Calder \& Young, 2005), such findings appear to rule out the strong view that in analogy to AP, developmental prosopagnosia is caused by the elimination of one or more parts of the core face-processing system. However, and in contrast to findings of apparent residual normality of face-specific brain activity in DP, there are also reports of other individuals with DP who do not show any face-selective activation of the core face network (Bentin, DeGutis, D'Esposito, \& Robertson, 2007), or show no face-selective responses at all (Duchaine, 2011; Duchaine et al., 2006). In summary, the fMRI studies to date do not afford any clear-cut inferences with respect to the architecture of the faceprocessing system in DP, or with regard to the question of whether the standard neuropsychological approach can provide an appropriate account of the face-processing deficits found in individuals with DP.

While functional neuroimaging studies can inform about the location and connectivity of brain regions involved in face processing, and how these are affected in AP and DP, they lack crucial information about the time-course of face perception and recognition, as it unfolds in the first few hundred milliseconds after a specific face is encountered. EEG and MEG can provide this fine-grained temporal information, which is important to gain insights into the architecture of human face processing in the typical case, and to contrast these insights with observations from patients with AP and participants with DP. In the next two sections, we will review results from recent studies that measured ERP correlates of face perception and face recognition in developmental prosopagnosia. We will also discuss the implications of these findings for our understanding of the mechanisms that are responsible for DP, against the background of both neuropsychological and neurodevelopmental accounts of developmental disorders.

\section{IMPAIRMENTS OF FACE PERCEPTION IN DEVELOPMENTAL PROSOPAGNOSIA: EVIDENCE FROM THE N170 COMPONENT}

A well-established early ERP marker of face-sensitive cortical processing is the N170 component (Bentin, Allison, Puce, Perez, \& McCarthy, 1996; Eimer, 2011; Rossion and Jacques, 2011). The N170 is measured as an enhanced negativity to faces as compared to non-face control stimuli that is triggered over lateral occipito-temporal electrodes between 150 and $200 \mathrm{~ms}$ after stimulus onset, and is often larger over the right 
hemisphere. N170 components have been linked to the perceptual categorization of a stimulus as a face (e.g., George, Jemel, Fiori, Chaby, \& Renault, 2005; Rossion and Jacques, 2008). The fact that the N170 is sensitive to face parts and facial configurations (Bentin et al., 1996; ZionGolumbic \& Bentin, 2007; Eimer, Gosling, Nicholas, \& Kiss, 2011), but not to the familiarity of a face (Bentin \& Deouell, 2000; Eimer, 2000a; Rossion et al., 1999; Schweinberger, Pickering, Jentzsch, Burton, \& Kaufmann, 2002), strongly suggests that this component is associated with the perceptual aspects of face encoding that precede subsequent stages involved in face recognition (Bruce \& Young, 1986). The face-sensitive N170 is usually accompanied by an enhanced positivity to faces, which is maximal at midline electrode $\mathrm{Cz}$ (Bötzel \& Grüsser, 1989; Jeffreys, 1989). This vertex positive potential (VPP) and the N170 component are closely associated and are often assumed to reflect the same underlying face-sensitive generator processes (e.g., Joyce \& Rossion 2005).

Importantly, the N170 is strongly affected by face inversion. Relative to upright faces, inverted faces trigger larger and delayed N170 components (e.g., Bentin et al., 1996; Eimer, 2000b; Rossion et al., 2000; Itier, Alain, Sedore, \& McIntosh, 2007). The factors that produce N170 face inversion effects are not yet fully understood (e.g., Sadeh \& Yovel, 2010). Some authors initially suggested that the enhancement of the N170 to inverted faces is linked to an inversion-induced disruption of face-specific configural processing and the resulting increased processing demands imposed by these faces (e.g., Rossion et al., 1999). However, the observation that activity in the face-selective fusiform and occipital face areas is actually reduced for inverted as compared to upright faces (Yovel \& Kanwisher, 2005) appears inconsistent with this proposal. Alternatively, N170 amplitudes may be larger for inverted faces because they activate additional neural populations, such as eye-selective neurons (Itier et al., 2007) or object-selective cells (e.g., Rossion et al., 2000), which are not activated by upright faces. In support of this latter hypothesis,
fMRI studies have demonstrated increased activation of object-selective regions when viewing inverted as compared to upright faces (e.g., Haxby et al., 1999), ERP investigations have shown distinct neural responses for upright versus inverted faces (Sadeh \& Yovel, 2010, Eimer et al., 2010; Rossion \& Jacques, 2008), and rTMS experiments have found that stimulating object-selective areas impairs the processing of inverted by not upright faces (Pitcher, Walsh, \& Duchaine, 2011b).

What have studies that measured the N170 component in individuals with AP or DP revealed about the nature of their face-processing impairments? The standard neuropsychological model makes clear predictions: if prosopagnosia were primarily or exclusively a deficit of early perceptual stages of face processing (apperceptive prosopagnosia; De Renzi, Faglioni, Grossi, \& Nichelli, 1991), there should be no differential N170 response to faces as compared to non-face objects in individuals with AP or DP. In contrast, if the origin of face-recognition deficits in $\mathrm{AP}$ and/or $\mathrm{DP}$ were primarily post-perceptual, such as deficits of long-term face memory, or disconnected links between face perception and face memory (associative prosopagnosia; De Renzi et al., 1991), the face-sensitivity of the N170 component should be preserved, and atypical ERP responses to faces should emerge only at longer latencies.

Results from those few studies that measured N170 components in patients with AP suggest close links between the structural and functional integrity of one or more components of the core face-processing system and the presence or absence of the N170. One early study from our lab found no differential N170 response to faces versus houses for patient PHD who has diffuse cortical damage including a focal left temporoparietal lesion (Eimer \& McCarthy, 1999), suggesting that his face-recognition problems are due to a disruption of early face-selective perceptual processing stages. More recently, Dalrymple et al. (2011) reported that the presence or absence of a face-selective N170 component in five patients with AP depended on whether their lesions included posterior face-sensitive regions

COGNITIVE NEUROPSYCHOLOGY, 2012, 00 (0) 
(fusiform and occipital face areas, posterior superior temporal sulcus). Additional cases also show that the N170 is not always completely eliminated in AP: Alonso-Prieto, Caharel, Henson, and Rossion (2011) found a preserved right-hemisphere N170 component over the right but not left hemisphere for prosopagnosic patient PS, whose lesions include the left fusiform and right occipital face areas (see also Bobes et al., 2004 for a preserved N170 in another patient with AP). Even fewer studies have measured inversioninduced N170 modulations in AP. Patient PHD showed no N170 amplitude difference between upright and inverted faces (Eimer \& McCarthy, 1999), consistent with the absence of any differential N170 modulation to faces versus houses in this patient, and further supporting an early perceptual locus of his face-processing deficit. In contrast, Alonso-Prieto et al. (2011) found that the N170 was enhanced in response to inverted versus upright faces in patient PS, suggesting that her prosopagnosic impairment may be located at a later post-perceptual stage of face processing.

Other ERP studies have investigated whether the face-sensitive N170 component is present or absent in individuals with DP. However, no clear pattern has emerged from these studies. Bentin, Deouell, and Soroker (1999) measured ERPs to faces and non-face objects for developmental prosopagnosic YT, whose core face-processing network appears to be largely intact (Hasson et al., 2003; see "Neuroimaging studies of AP and DP" above). The right-hemisphere N170 component was larger to faces than non-faces, but this difference was significantly smaller than the N170 modulations observed in 12 control participants. In another study, no statistically reliable N170 differences between faces and houses were found in two participants with DP (Kress and Daum, 2003; see also Bentin et al., 2007, for similar findings). Harris, Duchaine, \& Nakayama (2005) reported that three out of five DPs did not show the magnetic counterpart of the N170 (M170). Two participants were tested with EEG in the same study, and one of them showed a face-sensitive N170. Righart and De Gelder (2007) found enhanced N170 amplitudes in response to faces versus non-face objects for two DPs, but not for the other two DPs that were tested. Minnebusch et al. (2007) also tested four DPs and found a face-sensitive N170 component for three of them. Overall, the observation that some participants with DP do not show the typical N170 amplitude differences between faces and non-face objects may point towards a deficit in the early perceptual structural encoding of faces, or apperceptive prosopagnosia. However, the fact that other DPs showed a typical facesensitive N170 component despite severe facerecognition problems strongly suggests that this is by no means uniformly the case in DP, and that the neural and functional basis of DP can be highly variable across individuals.

To gain more systematic insights into the properties of the face-sensitive N170 component in developmental prosopagnosia, we recently tested a much larger sample of 16 participants with DP (Towler, Gosling, Duchaine, \& Eimer, submitted). They were presented with photographs of upright or inverted neutral or fearful faces and upright houses, and had to detect and respond to the immediate repetition of an image that was shown on the preceding trial (one-back task; see Eimer \& Holmes, 2002). In addition, a group of 16 control participants with intact face-recognition abilities was tested. As can be seen in Figure 1 (top right), the control group showed the typical face-sensitivity of the component. N170 amplitudes at right occipito-temporal electrode P8 were enhanced to upright neutral faces as compared to upright houses. Importantly, the results for the 16 participants with DP were very similar (Figure 1, top left): N170 amplitudes were again larger for faces versus houses, and the size of this effect did not differ statistically between the group of DPs and the control group. To check whether a face-sensitive N170 component was present or absent for individual DPs, we ran non-parametric bootstrap analyses (as described by Di Nocera \& Ferlazzo, 2000) for individual ERP datasets. These analyses revealed that 12 of the 16 DPs tested had reliably larger N170 amplitudes to faces relative to houses, and two others showed the same typical amplitude 
DP Group

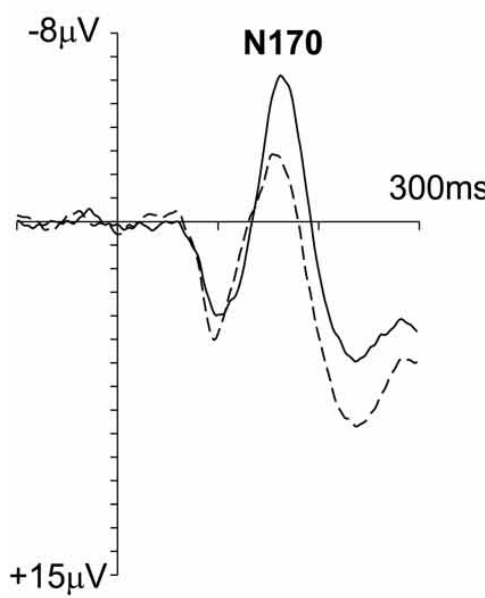

Control Group

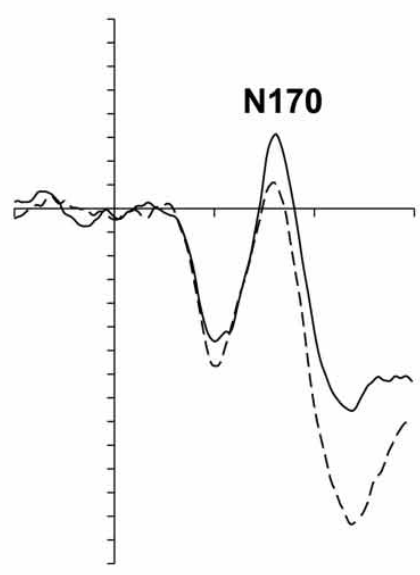

\section{N170 Difference Amplitudes}

Faces - Houses

(150-190 ms post-stimulus)

DP Group

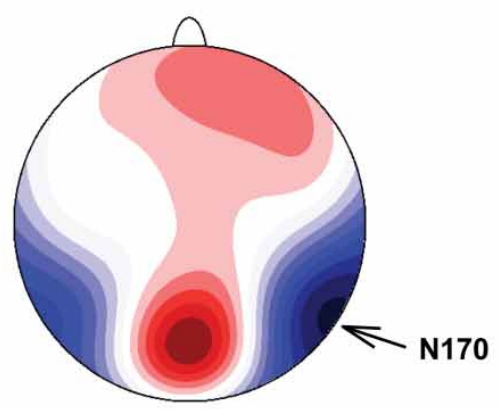

Control Group

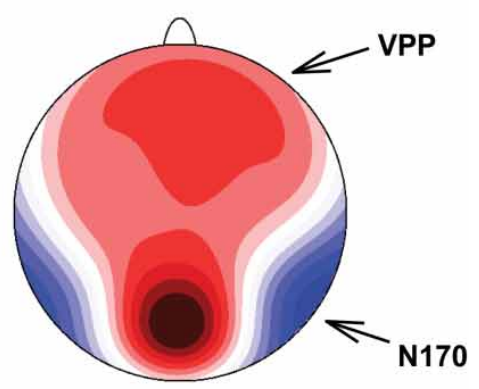

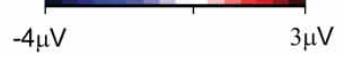

Figure 1. Top panels: Grand-averaged ERPs elicited by upright neutral faces and upright houses at right occipito-temporal electrode P8 in the $300 \mathrm{~m}$ interval after stimulus onset. ERPs are shown separately for a group of 16 DPs (left) and for a control group of 16 participants without $D P$ (right). Bottom panels: Topographic maps showing the scalp distribution of ERP difference amplitudes (upright neutral faces minus upright houses) in the N170 time window (150-190 ms post-stimulus), for the DP group (left) and the control group (right). Enhanced $N 170$ amplitudes to faces versus houses are triggered in a similar fashion in both groups, but the VPP component is only present in the control group. Data from Towler et al. (submitted). 
difference, which did not reach statistical significance. This was comparable to the N170 variability observed across control participants. Analogous results have been obtained in another recent study which found larger M170 components to faces versus places for all six DPs tested (Rivolta, Palermo, Schmatzl, \& Williams, 2012). These findings help to clarify the inconsistent pattern of findings from earlier studies, and strongly suggest that the presence of face-sensitive N170/M170 components is common in developmental prosopagnosia.

Figure 1 (bottom panels) shows topographic scalp distribution maps of difference amplitudes between upright faces and houses measured in our study (Towler et al., submitted) during the N170 time window (150-190 ms post-stimulus) for the DP group and for the control group. These maps further underline that face-sensitive N170 components were present over lateral occipito-temporal cortex in both groups. In the control group, the N170 was accompanied by the typical frontocentral positivity to faces versus houses (VPP; Jeffreys, 1989). In the DP group, no reliable VPP component was measured. However, this apparent VPP difference between DPs and controls observed was not statistically reliable in this study. It needs to be explored in future research whether dissociations in the facesensitivity of N170 and VPP components exist in DP.

Viewed from a standard neuropsychological perspective, the observation that the generic facesensitivity of the N170 was preserved for a large majority of the 16 DPs tested in our study would suggest that face perception is intact in DP, and that face-recognition deficits are caused by impairments that are located exclusively at later post-perceptual face processing stages, and may thus be categorized as associative prosopagnosia. However, the effects of face inversion on the N170 component that were obtained in the same study (Towler et al., submitted) suggest that such a conclusion would be incorrect. Figure 2 (top) shows ERPs to upright and inverted faces measured at right occipito-temporal electrode P8, for the 16 participants with DP (left), and for control participants (right). As expected, control participants showed typical N170 face inversion effects, with enhanced N170 components for inverted as compared to upright faces. In contrast, this face inversion effect on N170 amplitude was not observed for the DP group, and this difference between the two groups was statistically reliable. Analyses of individual ERPs revealed that only three of the 16 DPs tested showed typical effects of face inversion on N170 amplitudes. In fact, seven DPs actually exhibited the opposite pattern, with reliably larger N170 components to upright versus inverted faces. Face inversion also resulted in a significant delay of N170 peak amplitudes in the control group (Figure 2). This effect was smaller and not reliable in the DP group, but there was no significant difference in inversion-induced N170 latency shifts between the two groups.

It is important to consider the fact that the 16 DPs tested in our study (Towler et al., submitted) were between 22 and 67 years old, with a sizeable proportion of participants in their fifties. A recent ERP study (Gao et al., 2010) has shown that some N170 effects are age-sensitive. These authors tested young and elderly participants without documented face-processing impairments and found that the generic face-sensitivity of the N170 component was similar in the two groups, but that inversion-induced N170 amplitude enhancements were absent in the elderly. The fact that the DP and control participants included in our study were age-matched rules out the possibility that the absence versus presence of N170 face inversion effects was simply the result of age differences between groups. To illuminate age effects on inversion-induced N170 amplitude enhancements in DPs and controls, Figure 2 (bottom) shows N170 components to upright and inverted faces, separately for younger and older DPs and control participants. For DPs, age had no impact on N170 face inversion effects, which were absent not only in the older subgroup but also for young DPs. In contrast, the N170 enhancement for inverted faces commonly reported in the literature was present for young control participants but absent for older controls. 

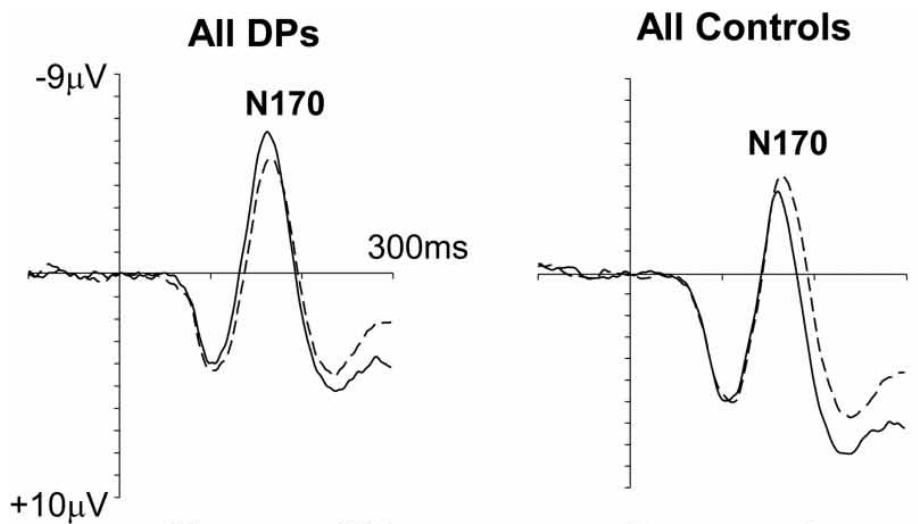

\section{Younger DPs}

(22-39 years)

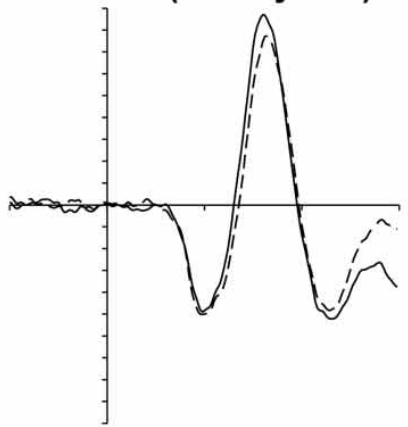

Older DPs
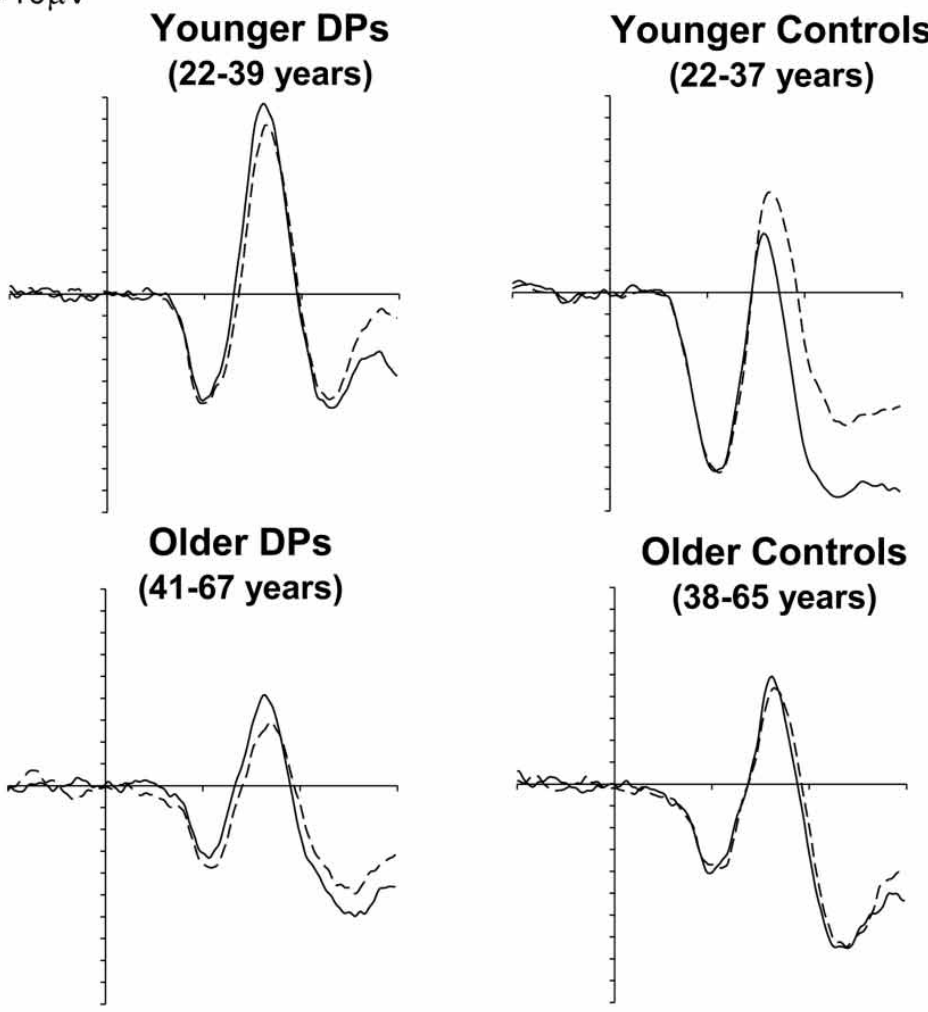

\section{- Upright Faces \\ ---- Inverted Faces}

Figure 2. Grand-averaged ERPs elicited by upright faces and inverted faces at right occipito-temporal electrode P8 in the $300 \mathrm{~ms}$ interval after stimulus onset. Top panel: ERP waveforms measured across all 16 DPs, and all 16 control participants without $D P$. The control group (right) shows typical face inversion effects on N170 amplitude. In the DP group (left), this effect is absent. Middle and bottom panels: ERPs shown separately for subgroups of younger and older DPs, and younger and older controls. Inversion-induced N170 amplitude enhancements were only present for younger control participants. Data from Towler et al. (submitted). 
These observations are similar to the results reported by Gao et al. (2010), except for the fact that their old participants were between 61 and 85 years old, whereas the age range of our older controls was $38-65$ years. This age bracket is rarely tested in ERP research, and our results suggest that deviations from the standard pattern of N170 results typically found with young adults might already emerge in middle age. More generally, these observations underline the critical importance of age matching for research on DP and other developmental disorders, in particular when employing measures that are sensitive to changes in underlying neural systems.

Evidence for atypical N170 face inversion effects in DP has been found in a previous single-case study (De Gelder \& Stekelenburg, 2005), and for three of four participants with DP in another study (Righart \& De Gelder, 2007). However, these findings were not substantiated by statistical analyses of individual ERPs, nor were DPs and controls matched by age, as controls in their early twenties were compared to DPs in their forties. The fact that such atypical effects were observed in our study for a much larger sample of DPs provides potentially important new evidence for specific perceptual faceprocessing impairments in DP that can emerge within $150 \mathrm{~ms}$ of stimulus onset. At first glance, the dissociation between the intact N170 facesensitivity and the presence of atypical N170 face inversion effects in DP is puzzling. Because the N170 component is associated with the perceptual sensory encoding of face stimuli, standard neuropsychological accounts would assume that focal lesions affecting this face-processing stage should be reflected by the absence of all facespecific N170 modulations, including both its sensitivity to faces versus non-face objects and its sensitivity to face inversion. On the other hand, if the face-sensitivity of the N170 is generally preserved in DP, this would indicate that the perceptual structural encoding of faces is unimpaired. Therefore, no atypical face inversion effects should be observed for the N170. The results observed in our study demonstrate that this line of reasoning is not correct.
It is important to note that the N170 component is not uniquely associated with a single aspect of face processing, but instead reflects distinct neural sources that appear to be linked to different face-sensitive brain mechanisms (e.g., Eimer et al., 2010; Rossion \& Jacques, 2008, 2011; Sadeh \& Yovel, 2010). For example, it has been demonstrated that the N170 is sensitive to specific face components, such as the eyes, even when these are presented in isolation (Bentin et al., 1996; Itier et al., 2007). The preserved face-sensitivity of the N170 that was observed for most DPs in our study may be a reflection of their ability to detect and encode individual face parts. However, the N170 is not just a marker of part-based face processing, but is also sensitive to other aspects of face perception, such as the configural or holistic analysis of face stimuli (e.g., Eimer et al., 2011). This is demonstrated by observations that $\mathrm{N} 170$ components are triggered in response to schematic faces versus non-faces (Sagiv \& Bentin, 2001) as well as to Mooney faces (Latinus \& Taylor, 2006; Eimer et al., 2011). Because configural/holistic face-processing stages are assumed to be selectively tuned to upright faces, the absence of typical N170 face inversion effects in DP suggests impairments at this level: unlike control participants, DPs may use similar neural systems to process both upright faces and inverted faces.

Overall, the observation that individuals with DP do not differ from individuals with normal face processing in terms of the generic face-sensitivity of the N170 component, but show atypical N170 face inversion effects, cannot be easily interpreted in terms of a simple neuropsychological model that postulates intact or damaged modules in the face processing system which are linked to the presence of absence of face-selective ERP components. Can an alternative neurodevelopmental approach provide a satisfactory explanation of these findings? To answer this question, it is useful to compare the pattern of N170 modulations observed in DP in response to upright faces, inverted faces, and non-face objects with results found in investigations of other developmental disorders. In addition, it should be 
informative to take account of observations from studies that have investigated the typical development of the N170 across infancy and childhood.

Interestingly, the absence of typical N170 face inversion effects does not appear to be restricted to DP, but can also be found in individuals with other types of developmental disorders. In a study of 32 high-functioning participants with autism spectrum disorder (ASD), Webb et al. (2012) found normal face-sensitivity of the N170 to faces versus houses, but a reduction of inversion-induced N170 amplitude modulations relative to the effects observed for control participants. Further evidence for links between atypical effects of face inversion on the N170 component have been reported by Grice et al. (2001). These authors recorded ERPs in response to upright and inverted faces from eight individuals with ASD, eight individuals with WS, and eight control participants. Controls showed the typical pattern of enhanced and delayed N170 components to inverted versus upright faces. For individuals with $A S D$, inversion-induced modulations of N170 amplitudes were much reduced and effects on N170 latency absent. For WS individuals, N170 amplitude enhancements to inverted faces were completely absent, even though the usual latency delay was observed.

The similarity between the atypical N170 face inversion effects observed for individuals with ASD or WS and the atypical effects found for individuals with $\mathrm{DP}$ is intriguing, and may point to shared underlying deficits in face-processing across these three different developmental disorders. Webb et al. (2012) attributed the reduction of face inversion effects on N170 amplitudes in participants with ASD to a strong bias towards the part-based processing of both upright and inverted faces in this group. Along similar lines, Grice et al. (2001) refer to deficits in the integration of single facial features into a global-configural face representation as one core impairment of individuals with WS. An analogous account in terms of impaired configural face processing, and the resulting tendency to analyse both inverted and upright faces in a part-based fashion might explain the observed atypical face inversion effects in individuals with DP. Any such deficit in perceptual structural encoding processes that are selectively tuned to upright faces should result in impaired structural representations of familiar faces both perceptually and in visual memory, which could be responsible for some of the severe and persistent problems with face recognition that are reported by individuals with DP.

According to a neurodevelopmental approach, further insights into the nature of the atypical N170 face inversion effects observed in individuals with DP might also be obtained by studying the developmental trajectory of the N170 component in typically developing individuals. Differential ERP responses to faces as compared to non-face objects have been found in young children and even for six-month-old infants (De Haan, Pascalis, \& Johnson, 2002; De Haan, Johnson, \& Halit, 2003; Halit et al., 2003). Because the "infant N170" initially emerges about $100 \mathrm{~ms}$ later than the N170 in adults, it is also referred to as N290 component (De Haan et al., 2003). From the age of four years onwards, the latency of the face-sensitive N170 component appears to resemble the latency typically observed in adult participants. In fact, the N170 appears to be remarkably stable in terms of its face-sensitivity, amplitude, and scalp topography between the ages of four and 17 years (Kuefner, de Heering, Jacques, Palmero-Soler, \& Rossion, 2010). These findings suggest that the face-sensitive perceptual processes that are responsible for differential N170 responses to faces versus non-face objects develop rapidly, are already present in a relatively adult-like form from early childhood, and do not change substantially throughout development. These insights from developmental studies are relevant for interpreting the apparently normal facesensitivity of the N170 component in individuals with DP. If the neural processes that produce this face-sensitivity are established early in the development of face processing, the presence of typical N170 responses to faces versus non-face objects in individual DPs may point to developmental deficits that originate at a somewhat later stage. In this context, the absence of age-appropriate face-sensitive N170 components in individual

COGNITIVE NEUROPSYCHOLOGY, 2012, 00 (0) 
DPs would be particularly interesting, as it would suggest that their face-processing impairments might have been present since early infancy, or even from birth (Behrmann \& Avidan, 2005).

In contrast to the generic face-sensitivity of the $\mathrm{N} 170$, which seems to emerge in an adult-like fashion early during development, typical N170 face inversion effects develop much later. This was demonstrated by Taylor et al. (2004) on the basis of a reanalysis of four ERP studies that tested children between four and 15 years of age, as well as adult participants. The developmental trajectory of face inversion effects on N170 latencies and amplitudes is shown in Figure 3. Intriguingly, the typical pattern found with younger adults (larger and later N170 components to inverted versus upright faces) only began to emerge around the age of 11-12 years. For younger children, there were no consistent face inversion effects on N170 latency. The typical adult inversion-induced N170 amplitude modulation was reversed for the three youngest age groups, with larger N170 components for upright relative to inverted faces (see also Passarotti, Smith, DeLano, \& Huang, 2007, for fMRI correlates of developmental differences in inverted face processing). This developmental pattern is relevant for the interpretation of the atypical N170 face inversion effects observed in our study for participants with DP. Almost half of all DPs tested in this study showed larger N170 components to upright as compared to inverted faces. In other words, these DPs showed N170 face inversion effects that would be typical for children below the age of 11 years.

When considered together with data from studies of the typical development of face processing, the presence of atypical N170 face inversion effects in DP can be interpreted as evidence that individuals with DP show some hallmarks of developmental delay and/or deviance in their perceptual face processing abilities. Put differently, some aspects of the response profile of their faceprocessing system resemble the typical case at much earlier points in developmental time. Because N170 face inversion effects observed

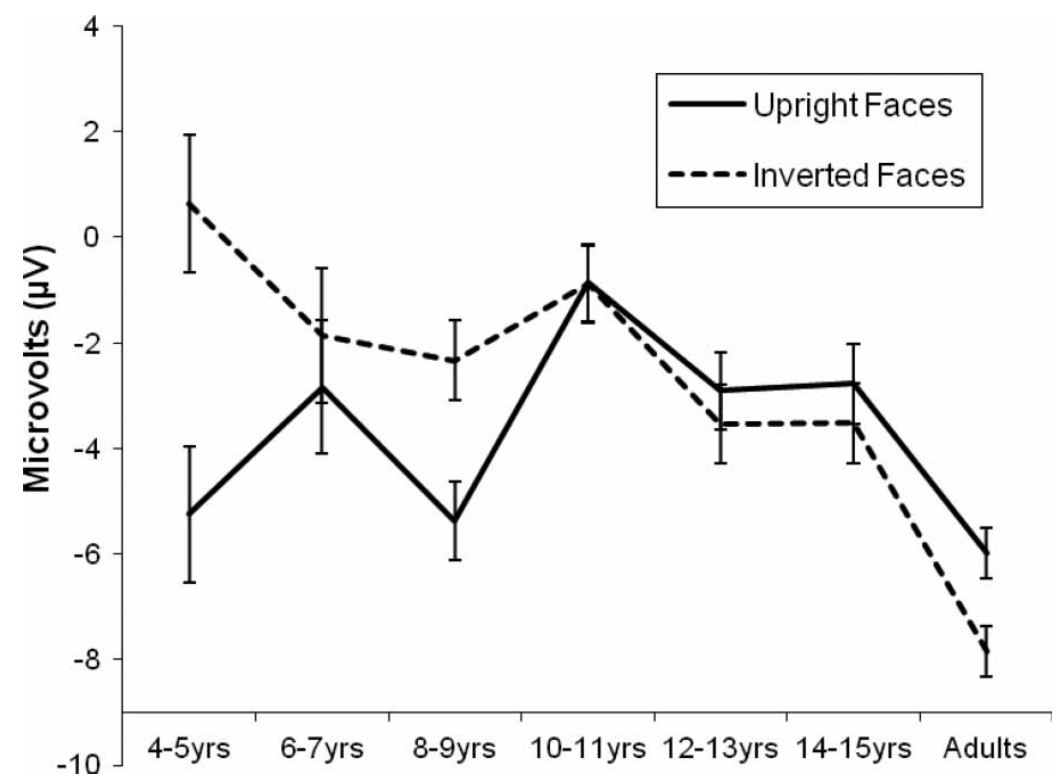

Figure 3. Effects of face inversion on $N 170$ amplitudes, shown separately for different age groups. Typical adult N170 face inversion effects (more negative $N 170$ amplitudes for inverted versus upright faces) are only apparent for the three oldest age groups. Children below the age of 10 years show the opposite effect (larger N170 components to upright faces). Data from Taylor et al. (2004). 
during typical development show a systematic trajectory towards the patterns observed in adulthood, they could provide valuable markers for the emerging tuning of face perception to canonically oriented upright faces. In this context, the presence of atypical N170 face inversion effects in DP may provide important clues with respect to the point in the development of face perception where selective processing deficits first emerge. Such an interpretation of N170 face inversion effects also needs to take account of the differences observed between younger and older control participants (Figure 2). We will return to this point in the final section.

\section{EXPLICIT AND COVERT FACE RECOGNITION IN DEVELOPMENTAL PROSOPAGNOSIA: EVIDENCE FROM THE N250 COMPONENT}

As discussed in the previous section, the N170 component is linked to early perceptual stages of face processing that precede the explicit recognition and identification of individual faces. Because DPs are specifically impaired in their ability to recognize or identify familiar faces, they may also show atypical patterns of ERP components that are more directly associated with face recognition. In typical adult participants, ERP markers of identity-related face processing first emerge at post-stimulus latencies of about 250 $\mathrm{ms}$. An enhanced occipito-temporal negativity is elicited in response to the faces of personally known or famous individuals, as well as to the repeated presentation of a previously unfamiliar face (e.g., Schweinberger, Pfütze, \& Sommer, 1995; Tanaka, Curran, Porterfield, \& Collins, 2006; Gosling \& Eimer, 2011). This N250 component is assumed to reflect the activation of a stored representation of a specific face in visual memory that is triggered when there is a match with a currently presented face. It is typically followed by a broadly distributed sustained positivity (P600f) to familiar faces (Eimer, 2000a; Bentin \& Deouell, 2000). The P600f has been linked to later stages of face recognition, such as name retrieval or access to semantic information about a specific individual (e.g., Gosling \& Eimer, 2011).

Because ERP research into the neural basis of $\mathrm{AP}$ and DP has so far focused on the N170 component, little is known about how ERP components associated with face recognition such as the N250 or P600f are affected in prosopagnosia. In one study of face recognition in AP (Eimer, 2000a), ERPs to famous and non-famous faces were measured for patient PHD. As reported earlier, this patient did not show any N170 faceselectivity (Eimer \& McCarthy, 1999), demonstrating damage to early perceptual stages of face processing. PHD did also not show any evidence for identity-sensitive ERP components at longer latencies. This would be predicted by neuropsychologically inspired models of adult face processing (e.g., Bruce \& Young, 1986), as deficits at the level of structural encoding should have detrimental knock-on effects on later stages of face recognition and identification.

A recent study conducted in our lab (Eimer, Gosling, \& Duchaine, 2012) was designed to specifically investigate ERP markers of face recognition for a group of 12 participants with DP. They watched sequentially presented photographs of famous and non-famous faces, and had to categorize them in terms of their identity. Each face could be classified as definitely known, familiar, unfamiliar, or definitely unknown. Famous faces were those of actors, politicians, musicians, sports personalities, and other celebrities well known in the UK. Controls correctly classified more than $80 \%$ of these famous faces as known or familiar (Gosling \& Eimer, 2011), whereas DPs recognized less than $30 \%$ of the same famous faces. Figure 4 (top left) shows ERPs measured at right occipito-temporal electrode P8 to famous faces on those relatively few trials where DPs correctly classified these faces as known or familiar, and to non-famous faces that were correctly judged to be unfamiliar/unknown. This figure also includes a topographical map of ERP difference amplitudes between these famous and non-famous faces in the N250 time window (230-400 ms post-stimulus). For comparison, analogous ERP waveforms and

COGNITIVE NEUROPSYCHOLOGY, 2012, 00 (0) 


\section{Explicit Face Recognition}
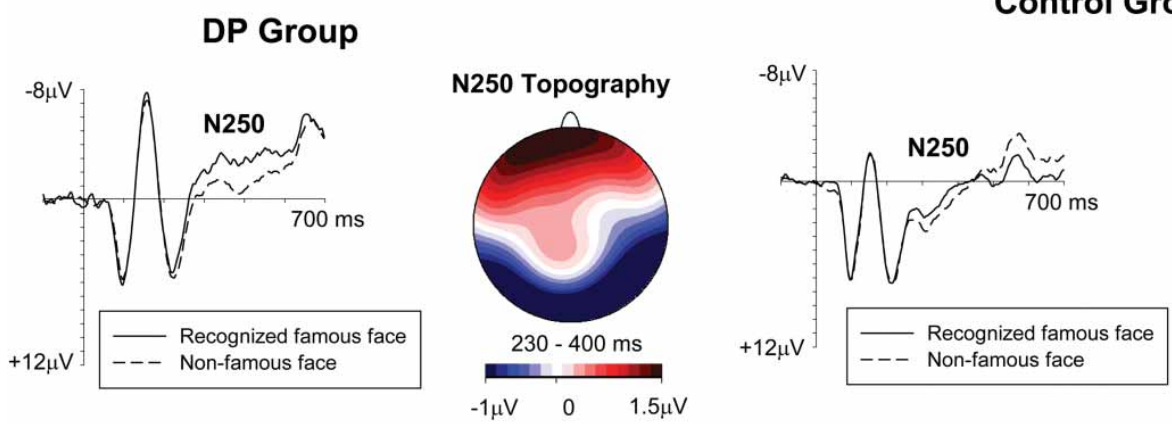

N250 Topography

\section{Covert Face Recognition}
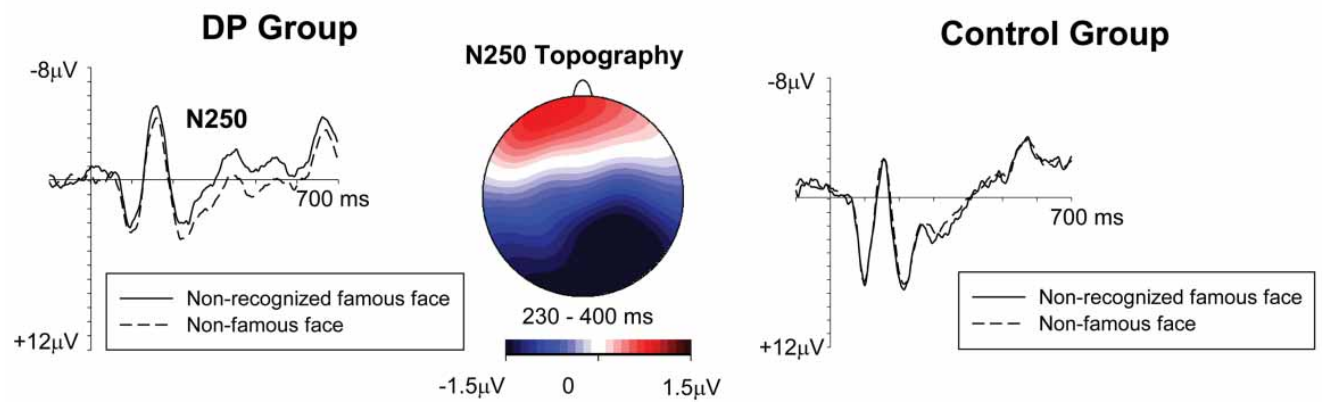

Figure 4. Top panels: ERP correlates of explicit face recognition in a group of 12 participants with DP (left) and 12 control participants (right). Grand-averaged ERPs to recognized famous faces and to non-famous faces classified as unfamiliar or unknown triggered at electrode P8 are shown together with topographic maps of ERP difference amplitudes (recognized famous faces minus non-famous faces) in the N250 time window (230-400 ms post-stimulus). N250 components to successfully recognized famous faces are very similar in both groups. Bottom panels: ERP correlates of covert face recognition for those six participants with DP who showed a reliable N250 to non-recognized famous faces (left), and 12 control participants who did not show any covert recognition effects (right). Grand-averaged ERPs to non-recognized famous and non-famous triggered at P8 are shown together with topographic maps of ERP difference amplitudes (recognized famous faces minus non-famous faces) in the N250 time window for six DPs who showed N250 covert recognition effects. Data from Eimer et al. (2012).

scalp topographies are also provided for a control group (Gosling \& Eimer, 2011; top right). As is evident from Figure 4, participants with DP showed an N250 component in response to those few famous faces that they were able to recognize successfully, suggesting the activation of visual face memory. Interestingly, their N250 component was in fact very similar in terms of its latency, amplitude, and scalp distribution to the N250 component observed in response to recognized famous faces for control participants (Figure 4, top right). The occipito-temporal N250 was followed by a more broadly distributed P600f component to correctly recognized famous faces that was maximal at midline electrodes (not shown in Figure 4), and this was the case for DPs as well as controls. These similarities between groups suggest that there are no fundamental qualitative differences in the brain mechanisms that underlie the successful recognition of famous faces between these two groups.

However, a remarkable difference between participants with and without DP emerged in the analysis of ERPs that were elicited by those famous faces that were not recognized, but were classified as unfamiliar or unknown (Figure 4, bottom). None of the typical adults tested (Gosling \& Eimer, 2011) showed any reliable 
ERP differences between non-recognized famous faces and non-famous faces that were correctly classified as unfamiliar or unknown. In other words, there was no electrophysiological evidence for covert face recognition (Diamond, Valentine, Mayes, \& Sandel, 1994) in these participants. In contrast, a clear and statistically reliable N250 component was observed in response to nonrecognized famous faces for six of the 12 DPs tested. Moreover, the scalp topography of this component (Figure 4, bottom left) was similar to the topography observed for explicitly recognized faces. Even though these six DPs classified the majority of famous faces as unfamiliar or unknown, N250 components clearly distinguished between these famous faces and objectively non-famous faces. These results suggest that many famous faces that were not recognized by participants with DP did activate stored visual representations of familiar faces. They also indicate that the activation of these visual representations is not sufficient for overt face recognition, in line with current functional models of normal face processing (Bruce and Young, 1986; Burton et al., 1990). Conscious recognition may require that faces are also processed at subsequent post-perceptual semantic stages, which are associated with the later P600f component. Interestingly, non-recognized famous faces did not trigger a P600f component, even for those DPs who showed covert recognition effects for the N250 component, which further substantiates the link between the P600f and conscious face recognition.

The identification of the N250 component as an electrophysiological marker of covert face recognition in DP extends previous behavioural findings by Avidan and Behrmann (2008) and Rivolta, Palermo, Schmalzl, \& Coltheart (2012a). Overall, these observations can be readily interpreted by a standard neuropsychological account. The presence of an N250 component to non-recognized famous faces in some individuals with DP indicates that these faces were able to successfully activate corresponding representations in visual memory, even though there was no overt recognition. Together with the fact that the P600f component was absent for the same faces, this observation points towards a relatively late locus of face-recognition impairments for these DPs. Functionally, their deficit appears to be caused by a disruption of the links between stored visual representations of familiar individuals and semantic or episodic representations in long-term memory. In other words, their profile could resemble that of patients with acquired associative prosopagnosia (De Renzi et al., 1991). In contrast, for those other six DPs who showed no N250 component to non-recognized famous faces, the core face processing deficit may be located at an earlier stage, such as the impaired structural descriptions of faces, and/or poor representations of familiar faces in visual memory (e.g., Schweinberger \& Burton, 2003). In this sense, they could be similar to patients with acquired apperceptive prosopagnosia (De Renzi et al., 1991).

Overall, the pattern of identity-sensitive ERP components observed for participants with DP appears to provide evidence for considerable residual normality of face recognition. As expected, individuals with DP were much less likely than controls to recognize images of famous faces. However, on those relatively infrequent occasions where face recognition was successful, it was accompanied by the same pattern of N250 and P600f components that was observed during explicit face recognition in participants with normal face recognition, suggesting qualitatively similar neural processes in the two groups (Eimer et al., 2012). This is in line with fMRI results discussed previously, which demonstrate a substantial degree of functionality in the visual areas responsible for face recognition, at least in some DPs (e.g., Avidan et al., 2005). From an adult neuropsychological perspective, the presence of N250 components as markers of covert face recognition in some participants with DP, and the absence of such covert recognition effects in others, may reflect apperceptive and associative subtypes of DP; that is, selective deficits at relatively early or late stages, or severed links between specific subprocesses, within an otherwise intact face-processing system. This interpretation is in line with functional imaging studies

COGNITIVE NEUROPSYCHOLOGY, 2012, 00 (0) 
showing that disconnection between the core ventral occipito-temporal regions and the extended face network is implicated in face-recognition difficulties in DP (e.g., Avidan \& Behrmann, 2009; Thomas et al., 2009).

How does the apparent residual normality of face recognition in DP relate to the atypical pattern of N170 effects observed for participants with DP? The N170 results discussed in "Impairments of face perception in developmental prosopagnosia" above suggest that aspects of the structural encoding of faces are atypical in DP, while the findings reported in this section show that DPs show an apparently typical pattern of N250 and P600f components during successful face recognition. This difference may be more apparent than real. There is now some evidence that N250 components are not exclusively associated with face recognition, but are instead a more general marker of successful matches between visual inputs and object representations stored in visual memory. For example, Scott, Tanaka, Sheinberg, and Curran (2006, 2008) observed N250 components during categorization tasks that required a within-class discrimination of objects (in particular objects of expertise), suggesting that the $\mathrm{N} 250$ is a generic reflection of a match between incoming visual information and visual memory. Its presence in individuals with DP indicates that although atypical face processing at early perceptual stages results in impaired visual face representations, a successful match with visual face memory is still possible on some occasions, and that the matching process itself operates normally.

\section{SUMMARY AND CONCLUSIONS}

This review of research into the neural basis of face-processing deficits in DP, with its specific emphasis on recent ERP studies, had two objectives. The first aim was to discuss the implications of this research with respect to which face processing mechanisms are affected in individuals with DP. Another more theoretical aim was to consider whether a standard neuropsychological model of impairments of face-selective modules provides a satisfactory account of developmental prosopagnosia, or whether a wider neurodevelopmental perspective is also required.

In acquired prosopagnosia, the face-sensitive N170 component is often absent, in particular when lesions include core face-processing systems. Consistent with the neuropsychological model, this suggests close links between selective impairments in the structural encoding of faces and the structural integrity of posterior brain areas involved in face perception. In contrast, as discussed above, the face-sensitivity of the N170 component is present for most individuals with developmental prosopagnosia. This result adds an important temporal dimension to observations from MRI studies, because it demonstrates that the initial face-sensitive activation of these areas occurs rapidly in participants with DP; that is, within approximately $150 \mathrm{~ms}$ after stimulus onset. In this respect, face processing in DP appears to follow a similar time-course to face processing in typical individuals. However, the presence of a face-sensitive N170 component in most DPs does not imply that their face perception mechanisms operate in exactly the same fashion as in controls. There were reliable differences between DPs and control participants with respect to N170 enhancements caused by face inversion. At the group level, these effects were present for controls and absent for DPs. It is important to note that the presence of inversioninduced N170 amplitude enhancements was agedependent in the control group, as it was present for young but absent for older controls. However, the fact that these effects were absent in DPs regardless of their age provides clear evidence that the processing of upright versus inverted faces is atypical in DP.

This dissociation between typical N170 facesensitivity and atypical N170 face inversion effects in DP is difficult to reconcile with the dichotomy of a perceptual structural encoding module that is either intact or damaged. A different perspective for the interpretation of these findings is offered by an alternative neurodevelopmental account. The presence of atypical N170 face inversion 
effects does not appear to be restricted to DP, but has been observed also for other developmental disorders such as ASD and WS (Grice et al., 2001; Webb et al., 2012). In addition, the absence of inversion-induced N170 amplitude modulations for participants with DP is reminiscent of the pattern observed for typically developing children below the age of 11 years (Taylor et al., 2004), and apparently also for older adults without faceprocessing impairments (Gao et al., 2010). In contrast, the generic face-sensitivity of the N170, which is largely preserved in DP, is already present at a much earlier stage of the typical development of the face-processing system (Kuefner et al., 2010). If the trajectory of the N170 component across development reflects the gradual tuning of face perception mechanisms towards the typical young adult state, the pattern of N170 effects observed for individuals with DP suggests that their face perception has never reached this end state, because its development was delayed or has deviated from this typical trajectory at a specific point during developmental time.

As discussed above, the presence of inversioninduced N170 amplitude enhancements is often regarded as evidence that only inverted and not upright faces are able to recruit object-selective neurons (e.g., Rossion et al., 2000). In this context, the absence of N170 differences between upright and inverted faces can be interpreted as evidence for an enhanced capacity of upright faces to activate object-selective areas, or, more generally, for a reduction in the face-specificity of visual processing. The observation that N170 face inversion effects are absent in young children and older adults, as well as in individuals with DP or other developmental disorders, may be an important pointer towards less face-selective functional specialisation within ventral visual areas in these groups. In support of this hypothesis, it has been shown that activation in face-selective regions becomes progressively more specialized through childhood into adulthood (Golarai et al., 2007), and that these face-selective regions become less differentiated and specialized with age (Park et al., 2004; Goh, Suzuki, \& Park, 2010). Furthermore, individuals with ASD show reduced or atypical neural specialization for faces (e.g. Schultz et al., 2000; Pierce, Muller, Ambrose, Allen, \& Courchesne, 2001). Atypical N170 face inversion effects and reduced levels of face-specific functional specialization could both be linked to a reduction in the connectivity of the right inferioroccipital fasciculus, which has been observed for a small group of DPs (Thomas et al., 2009), and is also associated with an age-related decline of face perception (Thomas et al., 2008). It should be noted that individuals with WS do not show a reduction in face selectivity, but instead have larger FFAs than matched controls, again demonstrating an atypical neural specialization for faces (Golarai et al., 2010).

While the presence of atypical N170 face inversion effects points to observable differences in the neurodevelopmental history of the face-processing architecture in individuals with and without DP, the pattern of identity-sensitive ERP components described above provides evidence for functionally and neurally similar face-recognition mechanisms in both groups. N250 and P600f components in response to successfully recognized famous faces were very similar for a group of DPs and for control participants (Eimer et al., 2012), suggesting that the same neural processes were active during face recognition in the two groups. In particular, the presence of an apparently normal N250 component in individuals with DP (see Figure 4) demonstrates that at least on some occasions, stored representations of familiar faces in visual memory were successfully activated by incoming perceptual face representations. The fact that DPs were much less likely than controls to recognize items from the same set of famous faces may be due to the impaired structural encoding of currently presented faces, the poor quality of stored visual representations of familiar faces (see Grüter, Grüter, Bell, \& Carbon, 2009, for impairments of visual imagery in DP), or a combination of the two factors. In addition, it appears that for a subset of DPs, face-recognition impairments are the result of severed links between stored face representations in visual memory and semantic or episodic memory.

We wish to conclude this review with one methodological and one more general theoretical point.

COGNITIVE NEUROPSYCHOLOGY, 2012, 00 (0) 
As regards methodology, neuroscientific research into acquired or developmental impairments of cognitive processing and their neural basis has often been conducted via single case studies or studies with very small sample sizes. This is also the case for most behavioural, ERP, and fMRI studies of DP. This approach is clearly problematic when investigating deficits that show considerable heterogeneity across individuals, as is likely to be the case for DP. Even though all DPs show severely impaired visual face recognition, the functional and neural basis of this deficit may be very different in different individuals, and this may account for the fact that many of the studies reviewed earlier have produced inconsistent or inconclusive results. For this reason, the use of larger sample sizes is one obvious requirement for future research into $\mathrm{DP}$ and its neural basis. In addition, research needs to focus not just on generic differences in face processing between larger groups of DPs and control participants, but also on possible differences in the functional and neural architectures that implement face processing across individuals with DP, as well as on age-related differences in DPs and control participants. These requirements necessitate a combined approach, where the analysis of differences between DPs and control participants at the group level is ideally complemented by the additional analysis of behavioural and neural measures at the individual level. Non-parametric bootstrap analyses (e.g., Di Nocera \& Ferlazzo, 2000) provide a useful tool to ascertain the reliability of the effects of specific experimental manipulations for individual participants. As discussed above, this combined case series approach may lead to new insights into distinct subtypes of DP and their neural basis.

The final theoretical point goes back to the important difference between neuropsychological and neurodevelopmental accounts of the origins of DP, as highlighted in the first section of this review. Proponents of an innate modular view of face processing and its developmental trajectory (e.g., Duchaine et al., 2006; McKone, Kanwisher, \& Duchaine, 2007) argue that core deficits may be located at a relatively high domain-specific level of cortical processing. Individuals with DP fail to develop a normally operating face-processing system, while other aspects of visual perception and cognition develop independently and normally, resulting in intact visual processing in non-face domains. In contrast, advocates of a neurodevelopmental perspective (e.g., Thomas \& Karmiloff-Smith, 2002) propose that the deficit responsible for developmental disorders such as DP will be explained by lower-level mechanisms which are domain-relevant, and that these effects will cascade into domain-specific processes over developmental time (Karmiloff-Smith, 1998). As a consequence, the resulting impairments are not confined to a single innate module, but should be at least subtly evident across domains that rely on shared mechanisms for typical development. Furthermore, neurodevelopmental approaches to face processing (e.g., Johnson et al., 2009) explicitly acknowledge the possibility that the facespecificity of different brain regions can both increase and decrease in the course of development (see Joseph, Gathers, \& Bhatt, 2011, for evidence). This is very much consistent with our suggestion that a reduced or otherwise atypical level of functional specialization for faces in ventral visual cortex could be a core feature of DP and other developmental disorders.

Although there is ample evidence of protracted developmental change in face processing (e.g., Joseph et al., 2011; Taylor et al., 2004), others have recently argued that the role of experience in the development of face recognition may have been overestimated (e.g., McKone, Crookes, Jeffery, \& Dilks, in press). Future research into the development of DP will be relevant for this debate, and this research is likely to profit from taking both neuropsychological and neurodevelopmental perspectives into account. The fact that adult face processing is to some extent modular (Busigny et al., 2010; Moscovitch, Winocur, \& Behrmann, 1997) does not imply that it develops independently from other aspects of visual cognition, because there may be important contributions from lower-level domain-relevant mechanisms during development. Such mechanisms could include local biases in visual attention, the absence of attentional biases towards face-like 
stimuli or the eye region, difficulties in rapidly binding together spatially separate components of visual objects, or impairments of automatic within-category object individuation processes. The atypical operation of such processes may have a disproportionate impact during sensitive periods of early development when higher-level domain-specific visual processes are becoming established (e.g., Le Grand, Mondloch, Maurer, \& Brent, 2004). These cognitive and other lowlevel neural biases could contribute, either by themselves or in combination, to the impaired face recognition that we observe in adult DPs. In contrast to control participants, some individuals with DP perform better in response to local as compared to global elements of hierarchical Navon stimuli (Behrmann \& Avidan, 2005; Avidan, Tanzer, \& Behrmann, 2011; but see Duchaine, Yovel, \& Nakayama, 2007b, for different results), suffer less interference when processing aligned composite faces (Palermo et al., 2011), and often show no or reduced behavioural face inversion effects (e.g., Avidan et al., 2011). Interestingly, some DPs show a negative correlation between their local bias on a non-face Navon task and global interference on the composite face task (Avidan et al., 2011), which would not be predicted by innately modular accounts of their face processing deficits. Overall, such findings suggest that many individuals with DP show a bias towards the local part-based processing of visual objects. If such a bias emerges early, it could affect the typical development of a configural or holistic mode of face processing that is tuned to canonically oriented upright faces. A consequence of such a low-level but domain-relevant atypical bias of visual processing is that individuals with DP will never develop the special mechanisms used for upright face recognition and will consequently analyse both upright and inverted faces in a similar fashion, and thus are impaired in tasks that depend on the configural or holistic processing of upright faces.

While the ERP results discussed in this article are consistent with both modular and neurodevelopmental accounts of DP, they highlight the utility of an integrated approach whereby the process of typical and atypical development is considered alongside adult and neuropsychological evidence in the understanding of neurodevelopmental disorders. Even though research into the functional, neural and genetic basis of DP has only begun, one fact that has already become evident is the heterogeneity of this condition. The debate between proponents of modular neuropsychological and neuroconstructivist accounts of developmental prosopagnosia is certain to continue.

\footnotetext{
Manuscript received 18 November 2011

Revised manuscript received 6 July 2012

Revised manuscript accepted 13 July 2012

First published online 16 October 2012
}

\section{REFERENCES}

Alonso-Prieto, E., Caharel, S., Henson, R. N., \& Rossion, B. (2011). Early (N170/M170) face-sensitivity despite right lateral occipital brain damage in acquired prosopagnosia. Frontiers in Human Neuroscience, 5, 138.

Annaz, D., Karmiloff-Smith, A., Johnson, M. H., \& Thomas, M. S. C. (2009). A cross-syndrome study of the development of holistic face recognition in children with autism, Down syndrome, and Williams syndrome. Journal of Experimental Child Psychology, 102, 456-486.

Avidan, G., \& Behrmann, M. (2008). Implicit familiarity processing in congenital prosopagnosia. Journal of Neuropsychology, 2, 141-164.

Avidan, G., \& Behrmann, M. (2009). Functional MRI reveals compromised neural integrity of the face processing network in congenital prosopagnosia. Current Biology, 19, 1146-1150.

Avidan, G., Hasson, U., Malach, R., \& Behrmann, M. (2005). Detailed exploration of face related processing in congenital prosopagnosia: 2. Functional neuroimaging findings. Journal of Cognitive Neuroscience, 17, 1150-1167.

Avidan, G., Tanzer, M., \& Behrmann, M. (2011). Impaired holistic processing in congenital prosopagnosia. Neuropsychologia, 49, 2541-2552.

Barton, J. J. S. (2008). Structure and function in acquired prosopagnosia: Lessons from a series of 10

COGNITIVE NEUROPSYCHOLOGY, 2012, 00 (0) 
patients with brain damage. Journal of Neuropsychology, 2, 197-225.

Behrmann, M., \& Avidan, G. (2005). Congenital prosopagnosia: Face blind from birth. Trends in Cognitive Sciences, 9, 180-187.

Behrmann, M., Avidan, G., Gao, F., \& Black, S. (2007). Structural imaging reveals anatomical alterations in inferotemporal cortex in congenital prosopagnosia. Cerebral Cortex, 17, 2354-2363.

Behrmann, M., Avidan, G., Marotta, J. J., \& Kimchi, R. (2005). Detailed exploration of face-related processing in congenital prosopagnosia: 1 . Behavioral findings. Journal of Cognitive Neuroscience, 17, 1130-1149.

Bellugi, U., Lichtenberger, L., Jones, W., Lai, Z., \& St George, M. (2000). The neurocognitive profile of Williams syndrome: A complex pattern of strengths and weaknesses. Journal of Cognitive Neuroscience, 12, 7-29.

Bentin, S., Allison, T., Puce, A., Perez, E., \& McCarthy, G. (1996). Electrophysiological studies of face perception in humans. Journal of Cognitive Neuroscience, 8, 551-565.

Bentin, S., DeGutis, J. M., D’Esposito, M., \& Robertson, L. C. (2007). Too many trees to see the forest: Performance, ERP and fMRI manifestations of integrative congenital prosopagnosia. Journal of Cognitive Neuroscience, 19, 132-146.

Bentin, S., \& Deouell, L. Y. (2000). Structural encoding and identification in face processing: ERP evidence for separate mechanisms. Cognitive Neuropsychology, 17, 35-54.

Bentin, S., Deouell, L. Y, \& Soroker, N. (1999). Selective visual streaming in face recognition: Evidence from developmental prosopagnosia. NeuroReport, 10, 823-827.

Bishop, D. V. M. (1997). Cognitive neuropsychology and developmental disorders: Uncomfortable bedfellows. Quarterly Journal of Experimental Psychology: Human Experimental Psychology, 50, 899-923.

Bobes, M., Lopera, F., Dias Comas, L., Galan, L., Carbonell, F., Bringas, M. L., \& Valdes-Sosa, M. (2004). Brain potentials reflect residual face processing in a case of prosopagnosia. Cognitive Neuropsychology, 21, 691-718.

Bodamer, J. (1947). Die Prosop-Agnosie. (Die Agnosie des Physiognomieerkennens). Archiv für Psychiatrie und Nervenkrankbeiten, 179, 6-53.

Bötzel, K., \& Grüsser, O. J. (1989). Electric brain potentials evoked by pictures of faces and non-faces:
A search for face-specific EEG-potentials. Experimental Brain Research, 77, 349-360.

Brown, J., Johnson, M. H., Paterson, S., Gilmore, R., Longhi, E., \& Karmiloff-Smith, A. (2003). Spatial representation and attention in toddlers with Williams syndrome and Down syndrome. Neuropsychologia, 41, 1037-1046.

Bruce, V., \& Young, A. (1986). Understanding face recognition. British Journal of Psychology, 77, 305-327.

Burton, A. M., \& Bruce, V. (1992). I recognise your face but I can't remember your name: A simple explanation? British Journal of Psychology, 83, 45-60.

Burton, A. M., Bruce, V., \& Johnston, R. A. (1990). Understanding face recognition with an interactive activation model. British Journal of Psychology, 81, 361-380.

Busigny, T., Joubert, S., Felician, O., Ceccaldi, M., \& Rossion, B. (2010). Holistic perception of the individual face is specific and necessary: Evidence from an extensive case study of acquired prosopagnosia. Neuropsychologia, 48, 4057-4092.

Calder, A. J., Keane, J., Manes, F., Antoun, N., \& Young, A. W. (2000). Impaired recognition and experience of disgust following brain injury. Nature Neuroscience, 3, 1077-1078.

Calder, A. J., \& Young, A. W. (2005). Understanding the recognition of facial identity and facial expression. Nature Reviews Neuroscience, 6, 641-651.

Calder, A. J., Young, A. W., Rowland, D., Perrett, D. I., Hodges, J. R., \& Etcoff, N. L. (1996). Facial emotion recognition after bilateral amygdala damage: Differentially severe impairment of fear. Cognitive Neuropsychology, 13, 699-745.

Caramazza, A. (1986). On drawing inferences about the structure of normal cognitive systems from the analysis of patterns of impaired performance: The case for single-patient studies. Brain and Cognition, 5, 41-66.

Dalrymple, K., Oruç, I., Duchaine, B., Pancaroglu, R., Fox, C. J., Iaria, G., ... Barton, J. J. (2011). The neuroanatomic basis of the face-selective N170 in acquired prosopagnosia, a combined ERP/fMRI study. Neuropsychologia, 49, 2553-2563.

De Gelder, B., \& Stekelenburg, J. J. (2005). Naso-temporal asymmetry for the N170 for processing faces in normal viewers but not in developmental prosopagnosia. Neuroscience Letters, 376, 40-45.

De Haan, M., Johnson, M. H., \& Halit, H. (2003). Development of face-sensitive event-related potentials during infancy: A review. International Journal of Psychophysiology, 51, 45-58. 
De Haan, M., Pascalis, O., \& Johnson, M. H. (2002). Specialization of neural mechanisms underlying face recognition in human infants. Journal of Cognitive Neuroscience, 14, 199-209.

De Haan, E. H. F., Young, A. W., \& Newcombe, F. (1991). A dissociation between the sense of familiarity and access to semantic information concerning familiar people. European Journal of Cognitive Psychology, 3, 51-67.

Dehaene, S., Piazza, M., Pinel, P., \& Cohen, L. (2003). Three parietal circuits for number processing. Cognitive Neuropsychology, 20, 487-506.

De Renzi, E., Faglioni, P., Grossi, D., \& Nichelli, P. (1991). Apperceptive and associative forms of prosopagnosia. Cortex, 27, 213-221.

Deruelle, C., Mancini, J., Livet, M. O., Cassé-Perrot, C., \& de Schonen, S. (1999). Configural and local processing of faces in children with Williams syndrome. Brain and Cognition, 41, 276-98.

Di Nocera, F., \& Ferlazzo, F. (2000). Resampling approach to statistical inference: Bootstrapping from event-related potentials data. Behaviour Research Methods, Instruments \& Computers, 32, 111-119.

Diamond, B. J., Valentine, T., Mayes, A. R., \& Sandel, M. E. (1994). Evidence of covert recognition in a prosopagnosic patient. Cortex, 30, 377-393.

Donnai, D., \& Karmiloff-Smith, A. (2000). Williams syndrome: From genotype through to the cognitive phenotype. American Journal of Medical Genetics, 97, 164-171.

Duchaine, B. (2011). Developmental prosopagnosia: Cognitive, neural, and developmental investigations. In A. J. Calder et al. (Eds.), The Oxford handbook of face perception (pp. 821-838). Oxford, UK: Oxford University Press.

Duchaine, B., Germine, L., \& Nakayama, K. (2007a). Family resemblance: Ten family members with prosopagnosia and within-class object agnosia. Cognitive Neuropsychology, 24, 419-430.

Duchaine, B., \& Weidenfeld, A. (2003). An evaluation of two commonly used tests of unfamiliar face recognition. Neuropsychologia, 41, 713-720.

Duchaine, B., Yovel, G., Butterworth, E., \& Nakayama, K. (2006). Prosopagnosia as an impairment to facespecific mechanisms: Elimination of the alternative explanations in a developmental case. Cognitive Neuropsychology, 23, 714-747.

Duchaine, B., Yovel, G., \& Nakayama, K. (2007b). No global processing deficit in the Navon task in 14 developmental prosopagnosics. Social Cognitive and Affective Neuroscience, 2, 104-113.

Eimer, M. (2000a). Event-related brain potentials distinguish processing stages involved in face perception and recognition. Clinical Neurophysiology, 111, 694-705.

Eimer, M. (2000b). Effects of face inversion on the structural encoding and recognition of faces: Evidence from event-related brain potentials. Cognitive Brain Research, 10, 145-158.

Eimer, M. (2011). The face-sensitive N170 component of the event-related brain potential. In A. J. Calder et al. (Eds.), The Oxford handbook of face perception (pp. 329-344). Oxford, UK: Oxford University Press.

Eimer, M., Gosling, A., \& Duchaine, B. (2012). Electrophysiological markers of covert face recognition in developmental prosopagnosia. Brain, 135, 524-554.

Eimer, M., Gosling, A., Nicholas, S., \& Kiss, M. (2011). The N170 component and its links to configural face processing: A rapid neural adaptation study. Brain Research, 1376, 76-87.

Eimer, M., \& Holmes, A. (2002). An ERP study on the time course of emotional face processing. NeuroReport, 13, 427-431.

Eimer, M., Kiss, M., \& Nicholas, S. (2010). Response profile of the face-sensitive N170 component: A rapid adaptation study. Cerebral Cortex, 20, 2442-2452.

Eimer, M., \& McCarthy, R. (1999). Prosopagnosia and structural encoding of faces: Evidence from eventrelated potentials. NeuroReport, 10, 255-259.

Ellis, H. D., \& Young, A. W. (1990). Accounting for delusional misidentifications. British Journal of Psychiatry, 157, 239-248.

Ellis, A. W., \& Young, A. W. (1996). Human cognitive neuropsychology: A textbook with readings. Hove, UK: Psychology Press.

Flude, B. M., Ellis, A. W., \& Kay, J. (1989). Face processing and name retrieval in an anomic aphasic: Names are stored separately from semantic information about familiar people. Brain and Cognition, $11,60-72$.

Furl, N., Garrido, L., Dolan, R. J., Driver, J., \& Duchaine, B. (2011). Fusiform gyrus face selectivity relates to individual differences in facial recognition ability. Journal of Cognitive Neuroscience, 23, 1723-1740.

Gao, L., Xu, J., Zhang, B. W., Zhao, L., Harel, A., \& Bentin, S. (2010). Aging effects on early-stage face

COGNITIVE NEUROPSYCHOLOGY, 2012, 00 (0) 
perception: An ERP study. Psychophysiology, 46, 970-983.

Garrido, L., Furl, N., Draganski, B., Weiskopf, N., Stevens, J., Tan, G. C-Y., ... Duchaine, B. (2009). VBM reveals reduced grey matter volume in the temporal cortex of developmental prosopagnosics. Brain, 132, 3443-3455.

Gauthier, I., Behrmann, M., \& Tarr, M. J. (1999). Can face recognition really be dissociated from object recognition? Journal of Cognitive Neuroscience, 11, 349-370.

George, N., Jemel, B., Fiori, N., Chaby, L., \& Renault, B. (2005). Electrophysiological correlates of facial decision: Insights from upright and upside-down Mooney-face perception. Cognitive Brain Research, 24, 663-673.

Goh, J. O., Suzuki, A., \& Park, D. C. (2010). Reduced neural selectivity increases $\mathrm{fMRI}$ adaptation with age during face discrimination. NeuroImage, 51, 336-344.

Golarai, G., Ghahremani, D. G., Whitfield-Gabrieli, W., Reiss, A., Eberhardt, J. L., Gabrieli, J. D. E., \& Grill-Spector, K. (2007). Differential development of high-level visual cortex correlates with category-specific recognition memory. Nature Neuroscience, 10, 512-522.

Golarai, G., Hong, S., Haas, B. W., Galaburda, A. M., Mills, D. L., Bellugi, U., .. . Reiss, A. L. (2010). The fusiform face area is enlarged in Williams syndrome. Journal of Neuroscience, 30, 6700-6712.

Gosling, A., \& Eimer, M. (2011). An event-related brain potential study of explicit face recognition. Neuropsychologia, 49, 2736-2745.

Grice, S., Spratling, M. W., Karmiloff-Smith, A., Halit, H., Csibra, G., de Haan, M., \& Johnson, M. H. (2001). Disordered visual processing and oscillatory brain activity in autism and Williams syndrome. NeuroReport, 12, 2697-2700.

Grüter, T., Grüter, M., Bell, V., \& Carbon, C. C. (2009). Visual mental imagery in congenital prosopagnosia. Neuroscience Letters, 453, 135-140.

Halit, H., de Haan, M., \& Johnson, M. H. (2003). Cortical specialisation for face processing: Face-sensitive event-related potential components in 3- and 12-month-old infants. NeuroImage, 19, 1180-1193.

Happé, F. G. E., Brownell, H., \& Winner, E. (1999). Acquired 'theory of mind' impairments following stroke. Cognition, 70, 211-240.

Harris, A., Duchaine, B., \& Nakayama, K. (2005). Normal and abnormal face selectivity of the M170 response in developmental prosopagnosics. Neuropsychologia, 43, 2125-2136.

Hasson, U., Avidan, G., Deouell, L. Y., Bentin, S., \& Malach, R. (2003). Face-selective activation in a congenital prosopagnosic subject. Journal of Cognitive Neuroscience, 15, 419-431.

Haxby, J. V., Hoffman, E. A., \& Gobbini, M. I. (2000). The distributed human neural system for face perception. Trends in Cognitive Sciences, 4, 223-233.

Haxby, J. V., Ungerleider, L. G., Clark, V. P., Schouten, J. L., Hoffman, E. A., \& Martin, A. (1999). The effect of face inversion on activity in human neural systems for face and object perception. Neuron, 22, 189-199.

Itier, R. J., Alain, C., Sedore, K., \& McIntosh, A. R. (2007). Early face processing specificity: It's in the eyes!. Journal of Cognitive Neuroscience, 19, 1815-1826.

Jeffreys, D. A. (1989). A face-responsive potential recorded from the human scalp. Experimental Brain Research, 78, 193-202.

Johnson, M. H., Grossman, T., \& Cohen Kadosh, K. (2009). Mapping functional brain development: Building a social brain through interactive specialization. Developmental Psychology, 45, 151-159.

Joseph, J. E., Gathers, A. D., \& Bhatt, R. S. (2011). Progressive and regressive developmental changes in neural substrates for face processing: Testing specific predictions of the interactive specialization account. Developmental Science, 14, 227-241.

Joyce, C., \& Rossion, B. (2005). The face-sensitive N170 and VPP components manifest the same brain processes: The effect of reference electrode site. Clinical Neurophysiology, 116, 2613-2631.

Kanwisher, N. (2000). Domain specificity in face perception. Nature Neuroscience, 3, 759-763.

Kanwisher, N., \& Barton, J. J. S. (2011). The functional architecture of the face system: Integrating evidence from $\mathrm{fMRI}$ and patient studies. In A. J. Calder (Ed.), The Oxford handbook of face perception (pp. 111-129). Oxford, UK: Oxford University Press.

Kanwisher, N., McDermott, J., \& Chun, M. M. (1997). The fusiform face area: A module in human extrastriate cortex specialized for face perception. Journal of Neuroscience, 17, 4302-4311.

Kanwisher, N., \& Yovel, G. (2006). The fusiform face area: A cortical region specialized for the perception of faces. Philosophical Transactions of the Royal Society of London, Series B: Biological Sciences, 361, 2109-2128. 
Karmiloff-Smith, A. (1992). Beyond modularity: A developmental approach to cognitive science. Cambridge, MA: MIT Press.

Karmiloff-Smith, A. (1998). Development itself is the key to understanding developmental disorders. Trends in Cognitive Sciences, 2, 389-398.

Karmiloff-Smith, A. (2009). Nativism versus neuroconstructivism: Rethinking the study of developmental disorders. Developmental Psychology, 45, 56-63.

Karmiloff-Smith, A., Scerif, G., \& Ansari, D. (2003). Double dissociations in developmental disorders? Theoretically misconceived, empirically dubious. Cortex, 39, 161-163.

Karmiloff-Smith, A., Thomas, M., Annaz, D., Humphreys, K., Ewing, S., Brace, N., ... Campbell, R. (2004). Exploring the Williams syndrome face processing debate: The importance of building developmental trajectories. Journal of Child Psychology and Psychiatry, 45, 1258-1274.

Kennerknecht, I., Grueter, T., Welling, B., Wentzek, S., Horst, J., Edwards, S., \& Grueter, M. (2006). First report of prevalence of nonsyndromic hereditary prosopagnosia (HPA). American Journal of Medical Genetics, A140, 1617-1622.

Kennerknecht, I., Pluempe, N., \& Welling, B. (2008). Congenital prosopagnosia: A common hereditary cognitive dysfunction in humans. Frontiers in Bioscience, 13, 3150-3158.

Kress, T., \& Daum, I. (2003). Event-related potentials reflect impaired face recognition in patients with congenital prosopagnosia. Neuroscience Letters, 352, 133-136.

Kuefner, D., de Heering, A., Jacques, C., PalmeroSoler, E., \& Rossion, B. (2010). Early visually evoked electrophysiological responses over the human brain (P1, N170) show stable patterns of face-sensitivity from 4 years to adulthood. Frontiers in Human Neuroscience, 3, 67.

Laing, E., Butterworth, G., Ansari, D., Gsödl, M., Longhi, E., Panagiotaki, G., et al. (2002). Atypical development of language and social communication in toddlers with Williams syndrome. Developmental Science, 5, 233-246.

Latinus, M., \& Taylor, M. J. (2006). Face processing stages: impact of difficulty and separation of effects. Brain Research, 1123, 179-187.

Lee, Y., Duchaine, B., Nakayama, K., \& Wilson, H. (2010). Three cases of developmental prosopagnosia from one family: Detailed neuropsychological and psychophysical investigation of face processing. Cortex, 46, 949-964.
Le Grand, R., Mondloch, C. J., Maurer, D., \& Brent, H. P. (2004). Impairment in holistic face processing following early visual deprivation. Psychological Science, 15, 762-768.

Mahon, B. Z., \& Caramazza, A. (2009). Concepts and categories: A cognitive neuropsychological perspective. Annual Review of Psychology, 60, 27-51.

Malone, D. R., Morris, H. H., Kay, M. C., \& Levin, H. S. (1982). Prosopagnosia: A double dissociation between the recognition of familiar and unfamiliar faces. Journal of Neurology, Neurosurgery $\xi$ Psychiatry, 45, 820-822.

Mareschal, D., Johnson, M. H., Sirois, S., Spratling, M. W., Thomas, M. S. C., \& Westermann, G. (2007). Neuroconstructivism: Vol. I. How the brain constructs cognition. Oxford, UK: Oxford University Press.

McKone, E., Crookes, K., Jeffery, L., \& Dilks, D. D. (in press). A critical review of the development of face recognition: Experience is less important than previously believed. Cognitive Neuropsychology, Advance online publication. Retrieved June 30, 2012. doi: 10.1080/02643294.2012.660138

McKone, E., Crookes, K., \& Kanwisher, N. (2009). The cognitive and neural development of face recognition in humans. In M. S. Gazzaniga (Ed.), The cognitive neurosciences (4th ed., pp. 467-482). Cambridge, MA: MIT Press.

McKone, E., Kanwisher, N., \& Duchaine, B. C. (2007). Can generic expertise explain special processing for faces? Trends in Cognitive Sciences, 11, 8-15.

Minnebusch, D. A., Suchan, B., Ramon, M., \& Daum, I. (2007). Event-related potentials reflect heterogeneity of developmental prosopagnosia. European Journal of Neuroscience, 25, 2234-2247.

Moscovitch, M., Winocur, G., \& Behrmann, M. (1997). What is special about face recognition? Nineteen experiments on a person with visual object agnosia and dyslexia but normal face recognition. Journal of Cognitive Neuroscience, 9, 555-604.

Oliver, A., Johnson, M. H., Karmiloff-Smith, A., \& Pennington, B. (2000). Deviations in the emergence of representations: A neuroconstructivist framework for analysing developmental disorders. Developmental Science, 3, 1-23.

Palermo, R., Willis, M. L., Rivolta, D., McKone, E., Wilson, C. E., \& Calder, A. J. (2011). Impaired holistic coding of facial expression and facial identity in congenital prosopagnosia. Neuropsychologia, 49, 1226-1235.

Park, D. C., Polk, T. A., Park, R., Minear, M., Savage, A., \& Smith, M. R. (2004). Aging reduces neural

COGNITIVE NEUROPSYCHOLOGY, 2012, 00 (0) 25 
specialization in ventral visual cortex. Proceedings of the National Academy of Sciences of the United States of America, 101, 13091-13095.

Passarotti, A. M., Smith, J., DeLano, M., \& Huang, J. (2007). Developmental differences in the neural bases of the face inversion effect show progressive tuning of face-selective regions to the upright orientation. NeuroImage, 34, 1708-1722.

Pierce, K., Muller, R. A., Ambrose, J., Allen, G., \& Courchesne, E. (2001). Face processing occurs outside the fusiform 'face area' in autism: Evidence from functional MRI. Brain, 124, 2059-2073.

Pinker, S. (1999). Words and rules. London: Weidenfeld $\&$ Nicolson.

Pitcher, D., Duchaine, B., Walsh, V., Yovel, G., \& Kanwisher, N. (2011). The role of lateral occipital face and object areas in the face inversion effect. Neuropsychologia, 49, 3448-3453.

Pitcher, D., Walsh, V., \& Duchaine, B. (2011). The role of the occipital face area in the cortical face processing network. Experimental Brain Research, 209, 481-493.

Righart, R., \& De Gelder, B. (2007). Impaired face and body perception in developmental prosopagnosia. Proceedings of the National Academy of Sciences of the United States of America, 104, 17234-17238.

Rivolta, D., Palermo, R., Schmalzl, L., \& Coltheart, M. (2012a). Covert face recognition in congenital prosopagnosia: A group study. Cortex, 48, 344-352.

Rivolta, D., Palermo, R., Schmatzl, L., \& Williams, M. A. (2012b). Investigating the features of the M170 in congenital prosopagnosia. Frontiers in Human Neurocience, 6, 45.

Rossion, B., Caldara, R., Seghier, M., Schuller, A.-M., Lazeyras, M., \& Mayer, E. (2003). A network of occipito-temporal face-sensitive areas besides the right middle fusiform gyrus is necessary for normal face processing. Brain, 126, 2381-2395.

Rossion, B., Delvenne, J. F., Debatisse, D., Goffaux, V., Bruyer, R., Crommelinck, M., et al. (1999). Spatiotemporal localization of the face inversion effect: An event-related potentials study. Biological Psychology, 50, 173-189.

Rossion, B., Gauthier, I., Tarr, M. J., Despland, P., Bruyer, R., Linotte, S., \& Crommelinck, M. (2000). The N170 occipito-temporal component is delayed and enhanced to inverted faces but not to inverted objects: An electrophysiological account of face-specific processes in the human brain. NeuroReport, 11, 69-74.
Rossion, B., \& Jacques, C. (2008). Does physical interstimulus variance account for early electrophysiological face sensitive responses in the human brain? Ten lessons on the N170. NeuroImage, 39, 1959-1979.

Rossion, B., \& Jacques, C. (2011). The N170: Understanding the time-course of face perception in the human bra. In S. Luck \& E. Kappenman (Eds.), The Oxford handbook of ERP components (pp. 115-142). Oxford, UK: Oxford University Press.

Sadeh, B., \& Yovel, G. (2010). Why is the N170 enhanced for inverted faces? An ERP competition experiment. NeuroImage, 53, 782-789.

Sagiv, N., \& Bentin, S. (2001). Structural encoding of human and schematic faces: Holistic and partbased processes. Journal of Cognitive Neuroscience, 13, 937-951.

Schultz, R. T., Gauthier, I., Klin, A., Fulbright, R. K., Anderson, A. W., Volkmar, F., ... Gore, J. C. (2000). Abnormal ventral temporal cortical activity during face discrimination among individuals with autism and Asperger syndrome. Archives of General Psychiatry, 57, 331-340.

Schweinberger, S. R., \& Burton, A. M. (2003). Covert recognition and the neural system for face processing. Cortex, 39, 9-30.

Schweinberger, S. R., Pfütze, E. M., \& Sommer, W. (1995). Repetition priming and associative priming of face recognition: Evidence from event-related potentials. Journal of Experimental Psychology: Learning, Memory and Cognition, 21, 722-736.

Schweinberger, S. R., Pickering, E. C., Jentzsch, I., Burton, A. M., \& Kaufmann, J. M. (2002). Eventrelated brain potential evidence for a response of inferior temporal cortex to familiar face repetitions. Cognitive Brain Research, 14, 398-409.

Scott, L. S., Tanaka, J. W., Sheinberg, D. L., \& Curran, T. (2006). A reevaluation of the electrophysiological correlates of expert object processing. Journal of Cognitive Neuroscience, 18, 1453-1465.

Scott, L. S., Tanaka, J. W., Sheinberg, D. L., \& Curran, T. (2008). The contributions of category experience and learning to perceptual expertise: A behavioural and neurophysiological study. Brain Research, 1210, 204-215.

Shallice, T. (1988). From neuropsychology to mental structure. Cambridge, UK: Cambridge University Press.

Steeves, J. K., Culham, J. C., Duchaine, B. C., Pratesi, C. C., Valyear, K. F., Schindler, I., ... Goodale, M. A. (2006). The fusiform face area is not sufficient 
for face recognition: Evidence from a patient with dense prosopagnosia and no occipital face area. Neuropsychologia, 44, 594-609.

Tanaka, J. W., Curran, T., Porterfield, A. L., \& Collins, D. (2006). Activation of preexisting and acquired face representations: The N250 event-related potential as an index of face familiarity. Journal of Cognitive Neuroscience, 18, 1488-1497.

Tarr, M. J., \& Gauthier, I. (2000). FFA: A flexible fusiform area for subordinate-level visual processing automated by expertise. Nature Neuroscience, 3, 764-769.

Taylor, M. J., Batty, M., \& Itier, R. J. (2004). The faces of development: A review of early face processing over childhood. Journal of Cognitive Neuroscience, 16, 1426-1442.

Thomas, M. S. C., \& Karmiloff-Smith, A. (2002). Are developmental disorders like cases of adult brain damage? Implications from connectionist modeling. Behavioral and Brain Sciences, 25, 727-780.

Thomas, C., Moya, L., Avidan, G., Humphreys, K., Jung, K. J., Peterson, M. A., \& Behrmann, M. (2008). Reduction in white matter connectivity, revealed by diffusion tensor imaging, may account for age-related changes in face perception. Journal of Cognitive Neuroscience, 20, 268-284.

Thomas, C., Avidan, G., Humphreys, K., Jung, K.-J., Gao, F., \& Behrmann, M. (2009). Reduced structural connectivity in ventral visual cortex in congenital prosopagnosia. Nature Neuroscience, 12, 29-31.

Towler, J., Gosling, A., Duchaine, B., \& Eimer, M. (submitted for publication). The face-sensitive N17O component in developmental prosopagnosia.

Webb, S. J., Merkle, K., Murias, M., Richards, T., Aylward, E., \& Dawson, G. (2012). ERP responses differentiate inverted but not upright face processing in adults with ASD. Social Cognitive and Affective Neuroscience, 7, 578-587.

Westermann, G., Mareschal, D., Johnson, M. H., Sirois, S., Spratling, M. W., \& Thomas, M. S. C. (2007). Neuroconstructivism. Developmental Science, 10, 75-83.

Wilmer, J. B., Germine, L., Chabris, C. F., Chatterjee, G., Williams, M., Loken, E., ... Duchaine, B. (2010). Human face recognition ability is highly heritable. Proceedings of the National Academy of Sciences of te United States of America, 107, 5238-5241.

Young, A. W. (1992). Face recognition impairments. Philosophical Transactions of the Royal Society of London, Series B: Biological Sciences, 335, 47-54.

Young, A. W. (2011). Disorders of face perception. In A. J. Calder et al. (Eds.), The Oxford handbook of face perception (pp. 77-91). Oxford, UK: Oxford University Press.

Young, A. W., \& Burton, A. M. (1999). Simulating face recognition: Implications for modelling cognition. Cognitive Neuropsychology, 16, 1-48.

Young, A. W., Newcombe, F., de Haan, E.H. F., Small, M., \& Hay, D. C. (1993). Face perception after brain injury: Selective impairments affecting identity and expression. Brain, 116, 941-959.

Yovel, G., \& Kanwisher, N. (2005). The neural basis of the behavioral face-inversion effect. Current Biology, 15, 2256-2262.

Zhu, Q. Song, Y., Hu, S., Li, X., Tian, M., Zhen, Z., .. . Liu, J. (2010). Heritability of the specific cognitive ability of face perception. Current Biology, 20, 137-142.

Zion-Golumbic, E., \& Bentin, S. (2007). Dissociated neural mechanisms for face detection and configural encoding: Evidence from N170 and induced gammaband oscillation effects. Cerebral Cortex, 17, 1741-1749. 